OPEN ACCESS

Edited by: Ippei Shimizu,

Niigata University, Japan

Reviewed by:

Mashito Sakai,

University of California, San Diego,

United States

Masataka Yokoyama,

Chiba University, Japan

*Correspondence:

Wawaimuli Arozal

wawaimuli@gmail.com;

wawaimuli.aroza/@ui.ac.id

Specialty section:

This article was submitted to Cardiovascular Metabolism,

a section of the journal

Frontiers in Cardiovascular Medicine

Received: 15 December 2019 Accepted: 16 April 2020 Published: 06 May 2020

Citation:

Arozal W, Louisa M and Soetikno V (2020) Selected Indonesian Medicinal

Plants for the Management of Metabolic Syndrome: Molecular Basis

and Recent Studies.

Front. Cardiovasc. Med. 7:82

doi: 10.3389/fcvm.2020.00082

\section{Selected Indonesian Medicinal Plants for the Management of Metabolic Syndrome: Molecular Basis and Recent Studies}

\author{
Wawaimuli Arozal*, Melva Louisa and Vivian Soetikno \\ Department of Pharmacology and Therapeutics, Faculty of Medicine, Universitas Indonesia, Jakarta, Indonesia
}

Increased prevalence of metabolic syndrome (MetS) in the world influences quality of health in all respective countries, including Indonesia. Data from Indonesian Family Life Survey reported in 2019 showed that the prevalence of MetS in Indonesia currently is $21.66 \%$, estimated with the provincial incidence ranging up to $50 \%$; additionally, the most common components of MetS discovered in Indonesia were poor high-density lipoprotein (HDL) cholesterol and hypertension. Management treatment of MetS involves a combination of lifestyle changes and pharmacological interventions to decrease cerebrovascular disease. Various natural substances have been shown to govern any cardiovascular or metabolic disorders through different mechanisms, such as triggering anti-inflammation, lipid profile correction, sensitization of insulin reception, or blood glucose control. In Indonesia, the utilization of natural compounds is part of the nation's culture. The community widely uses them; even though in general, their effectiveness and safety have not been thoroughly assessed by rigorous clinical trials. Scientific evidence suggested that cinnamon, mangosteen, and curcumin, as well as their derived components possess a broad spectrum of pharmacological activity. In this review, an enormous potential of cinnamon, mangosteen, and curcumin, which originated and are commonly used in Indonesia, could be treated against MetS, such as diabetes, hyperlipidemia, hypertension, and obesity. The findings suggested that cinnamon, mangosteen, curcumin and their derivatives may reflect areas of promise in the management of MetS.

Keywords: curcumin, cinnamon, mangosteen, Indonesia, metabolic syndrome

\section{INTRODUCTION}

Metabolic syndrome (MetS) represents a group of physiological abnormalities involving central obesity, hypertension, dyslipidemia, and insulin resistance, which are strongly associated with an increased risk of cardiovascular event and adult-onset diabetes mellitus (T2DM) (1). Researchers reported that the prevalence worldwide of MetS was increased in both developed countries and developing countries, including Indonesia, one of the most populated countries in the region of Southeast Asian countries $(2,3)$.

Indonesia is a massive archipelago country with a projected population of 226 million in 2018 (Indonesia Population 2018), consisting of 33 provinces and various ethnic groups (estimated about 
633), along with multiple cultures and lifestyles. A recent study from the Indonesian Family Life Survey, which is the first nationwide study regarding the prevalence and distribution of MetS in Indonesia, reported that its prevalence in Indonesia currently is $21.66 \%$. The prevalence was conformed with the approximation of global MetS prevalence (20-25\%) by the International Diabetes Federation (IDF) (IDF consensus worldwide 2006). The most common components of metabolic syndrome discovered in Indonesia were poor high-density lipoprotein (HDL) cholesterol and hypertension (3).

Along with modifying the underlying risk factors, the pharmacology therapy for MetS is aimed to treat the individual components of MetS (4). No single-drug therapy was available for MetS. The current pharmacotherapy is associated with treating comorbidities with chronic usage of multiple medications. Therefore, it is defying for patients to consume multiple drugs, leading to compliance reduction (5). Hence, the use of a natural compound in diminishing the risk of MetS is of interest, since the natural compounds seem to exhibit minimal side effects.

The results of a national survey in 2014-2015 showed a high prevalence of traditional medicines used in subjects with high blood sugar or heart problems, with about 9.9\% used traditional medicines and $11.2 \%$ mixed modern and traditional medicines (6). About 5,000 species of medicinal plants can be found from the Medicinal Herb Index in Indonesia. Empirically, Indonesian herbal medicines are most commonly used as Jamu, a freshly prepared plant material, usually in the form of water extracts (7). Medicinal plants previously used for MetS in Indonesia, includes Andrographis paniculata, Annona muricata, Zingiberis officinale, Cinnamomum burmanni, Garcinia mangostana, and Curcuma $\operatorname{spp}(7)$.

Diverse natural compounds extracted from herbal plants, such as turmeric, garlic, cinnamon, ginger, grapes, onions, and broccoli exhibit verifiable benefits in the treatment of patients' MetS with the various mechanisms of actions (8). However, these natural compounds are still under investigation and are not recommended as a replacement for standard pharmacotherapies. In Indonesia, the utilization of natural compounds is part of the nation's culture. The community widely uses them; even though in general, their effectiveness and safety have not been thoroughly assessed by rigorous clinical trials. Indonesia has vast biological resources and is one of the most bio-diversified nations after Brazil (9).

Here, we review the most common existing natural compounds originating from Indonesia, which are cinnamon, curcumin, and mangosteen that have been studied for their benefits in managing MetS.

\section{GENERAL DESCRIPTION}

\section{Cinnamon}

Cinnamon is a common herb that is commonly applied in food and industries. Its oil could be used in traditional medicine as an antiseptic, antitussive, antimicrobial, antioxidant, or pain reliever (2).

In Indonesia, cinnamon was mainly found in Kerici, Sumatera, with the species called Cinnamomum burmanni.
Availability of cinnamon for a long time in Indonesia, and it has become one of the primary commodities for trade since the Dutch colonization. The growth of Cinnamomum burmannii is optimally supported by the presence of mountainous land stretching along copious islands of Indonesia with enough rainfall. Cinnamomum burmannii is a shrub that is popularly recognized as the member of the Lauraceae family, such as Indonesian Cassia, Batavia Cassia, and Padang Cassia. It is widely distributed in Southeast Asia, cultivated in parts of Indonesia and Philippines possessing elliptical, green, anti parallelly arranged leaves and an ovoid-shaped fruit. The dried bark of the plant could be processed into rolls and quills for cooking. Cinnamon extract results in many chemical active compounds including flavonoids, phenols, alkaloids, quinones, steroids, saponins, and tannins $(2,10)$. Cinnamon's bark contains mainly procyanidins and catechins which are believed to result in pharmacological activity against type 2 diabetic and insulin resistance (11). In addition, cinnamon is also rich with essential oil mainly composed of eugenol and cinnamaldehyde which are known to be antimicrobial agents which exhibit a broad spectrum of activity (12).

\section{Mangosteen}

Mangosteen (Garcinia mangostana Linn.) is an indigenous tree widely found in Southeast Asia, mainly Indonesia (13). Mangosteen fruit is round with thick skin (also called pericarp) and exhibits a purple color. Local people used various parts of Garcinia mangostana Linn. for treatment of diarrhea, wound infection, and fevers (14). Extensive pharmacological activities of mangosteen and its active compounds have been identified in many studies previously. The effects include anticancer, antibacterial, and antimalarial, as well as for the treatment of Alzheimer's disease $(14,15)$.

The main compound in mangosteen is xanthones. Up to date, more than 60 xanthones have been isolated from mangosteen fruit pericarp. Among the xanthones, alphamangostin $(\alpha-M G)$ and gamma-mangostin are the most prevalent. Other xanthones found include beta-mangostin, gartanin, mangostinone, isomangostin, and garcinones $\mathrm{A}, \mathrm{B}$, C, D, and E (16). Interestingly, a study by Muchtaridi et al. demonstrated high variability of concentrations of alphamangostin and gamma-mangostin extracted from Garcinia mangostana taken from various regions in Indonesia (17).

\section{Curcumin}

Curcumin, which is mainly extracted from turmeric of the ginger family, is a polyphenol compound and used as a spice in Southeast Asian and East Asian countries, including Indonesia. Indonesia is a country with a wide diversity of Curcuma species, and it has been reported that Indonesia has 15 species of Curcuma in Java, among others are C. aurantiaca, C. zedoaria, C. phaeocaulis, C. xanthorrhiza, C. longa (18). Among the Curcuma species, Curcuma longa (turmeric) results in the highest amount of curcuminoids. The major curcuminoids discovered in the Curcuma longa are curcumin, bisdemethoxycurcumin, and demethoxycurcumin. It is poorly absorbed when given orally due to extensive first-pass hepatic metabolism to form major 
metabolites, like tetrahydrocurcumin and hexahydrocurcumin (19-21). To date, many studies demonstrated that curcumin can improve metabolic disorders. Several mechanisms have also been proposed to prove the mechanism of action of curcumin in association with these metabolic disorders. Ample evidence from in vitro and in vivo studies demonstrated that curcumin exhibits potent anti-inflammatory, antioxidant, anticancer, and antihyperglycemic activities $(22,23)$.

\section{EFFECTS OF CINNAMON, MANGOSTEEN AND CURCUMIN ON GLUCOSE LEVEL AND DIABETIC-RELATED OUTCOME}

\section{Cinnamon}

Studies conducted by Cao et al. (24) examined the effects of C. burmannii extract and cinnamon polyphenols (CP) on the expression of the insulin receptor, glucose transporter 4 (GLUT4), and tristetraprolin (TTP/ZFP36) in adipocytes. Western blotting showed that CP increased IR $\beta$ levels, while both aqueous extract and CP elevated GLUT4 and TTP expression in the lipid tissues. Real-time PCR indicated that aqueous extracts $(100 \mu \mathrm{g} / \mathrm{mL})$ rapidly boost TTP mRNA by nearly 6fold in the adipocytes. In fact, higher concentrations of $C$. burmanii decreased IR $\beta$ protein and mRNA quantity. Thus, the study proposed that the plant exhibits potential ability to enhance the process of metabolic transport and reactions, including insulin response, glucose transmembrane transport, and anti-inflammatory activity (24). Another study reported by Sheng et al. (25) concluded that cinnamon temporarily and competitively inhibits the alpha-glucosidase enzyme in improving symptoms of streptozotocin-induced diabetic rats. A study reported by Chen et al. (26) summarized that $C$. cassia and C. tammala extracts were rich in B and A type procyanidins oligomers, which are thought to be responsible for the antidiabetic activity of cinnamon. In this study, using diabetic $(\mathrm{db} / \mathrm{db})$ mice model which is a representative animal model for type 2 diabetic, they found that those 2 cinnamon extracts exhibit antidiabetic effects. Histopathological studies in pancreas, liver and adipose tissue showed that C. cassia promoted lipid accumulation in the liver and adipose tissue, whereas $C$. tammala improved the insulin concentration in the blood and pancreas (26).

A systematic review by Ranasinghe et al. (2) and Bandara et al. (27) on the effects of Cinnamon zeylanicum and Cinnamon aromaticum on diabetes mellitus, displayed a number of worthwhile effects both in vitro and in vivo, even though conflicting results were still under observation concerning supports from only few clinical trials. In vitro, C. zeylanicum reduced intestinal glucose assimilation by inhibiting activity of $\alpha$-glucosidase and $\alpha$-amylase. Furthermore, it stimulates cellular glucose uptake through direct expression of glucose transporter4, inhibiting gluconeogenesis, and promoting insulin release, as well as insulin sensitization. The beneficial effects of $C$. zeylanicum in the body consist of diabetes-associated weight loss control, HDL cholesterol booster, reduction of fasting blood glucose, and increasing circulating insulin levels. C. zeylanicum also dramatically improved metabolic disorders related with insulin resistance and complication of diabetic neuropathy and nephropathy, without side effects of drug induced liver injury $(2,27)$.

Moreover, in a placebo-controlled double-blind clinical trial, 58 subjects of type 2 diabetic patients with $\mathrm{HbA} 1 \mathrm{c}$ of more than $7 \%$ were treated with hypoglycemic agents plus $2 \mathrm{~g}$ of cinnamon or placebo daily for 12 weeks. At the end of the trial, $\mathrm{HbAlc}$ was significantly reduced in the cinnamon group (8.22-7.86\%) as compared with the placebo group (8.55-8.68\%). A reduction in mean systolic and diastolic blood pressure in the cinnamontreated group $(\mathrm{SBP}=132.6-129.2 \mathrm{mmHg}$; $\mathrm{DBP}=85.2-80.2$ $\mathrm{mmHg}$ ) also occurred compared with the placebo group ( $\mathrm{SBP}=$ 134.5-134.9 mmHg; DBP = 86.8-86.1 mmHg) (28).

A statistically significant subtraction of waist circumference, fasting plasma glucose, and body mass index was observed at month-3 compared to baseline in the cinnamon group; however, the changes were not different from the placebo with no significant differences shown in the total lipid profiles (29). Another clinical study reported the efficacy and safety of a novel bioactive substance (DLBS3233) extracted from Lagerstroemia speciosa and Cinnamomum burmanii in enhancing insulin sensitivity, as well as $\beta$-cell physiological function in patients with impaired glucose tolerance. DLBS3233 treated insulin resistance better than the placebo, represented through a lower value of HOMA-IR index. Restoration of the two-phase insulin secretion was constantly higher in the DLBS3233 group. Besides, DLBS3233 results in a much better oral disposition index than the placebo with no serious adverse events reported (30). Another double-blind, randomized, and placebo-controlled clinical trial reported the opposite result in which the type 2 diabetes patients were given either $3 \mathrm{~g} /$ day cinnamon supplement or a placebo. At the end of the intervention, alterations in the level of fasting blood glucose, insulin, HbA1c, HOMA-IR index, carboxymethyl lysine, total antioxidant capacity, and malondialdehyde were neither significant in both group nor between groups observed within these glycemic and inflammatory components (31).

\section{Mangosteen}

Studies describing the hypoglycemic efficacy of mangosteen were mostly done in streptozotocin-induced diabetes rat model (32-35). Streptozotocin is considered the most post potent diabetogenic chemical used for diabetic research (36). Its toxic effects are dependent on its accumulation on pancreatic beta cells and produce damage via DNA fragmentation (37). However, due to the nature of various contributing factors in MetS, a streptozotocin-induced animal model is not an ideal model to study hyperglycemia in MetS. A previous review suggested that the rat model that displayed the closest criteria to human MetS was by inducing a high-carbohydrate and high-fat diet $(38,39)$.

Ethanolic extract of Garcinia mangostana was shown to exhibit a potent hypoglycemic effect in streptozotocin-induced diabetes in rats given for 28 days, which was related to the increase in beta cell number in pancreatic islet (32).

In streptozotocin-induced cell damage, alpha-mangostin promotes expression of both phosphorylated insulin receptor and pancreatic duodenal homeobox 1 (Pdx1), therefore, improving 
insulin secretion in the INS-1 cells. The effect of alphamangostin in INS-1 cells was followed by the increased phosphorylation of PI3K/Akt and ERK signaling pathways. As a result, the phosphorylation of insulin receptor substrate (IRS-1-Ser1101) was inhibited. Moreover, treatment with alphamangostin decreases the phosphorylation of c-Jun N-terminal kinase (JNK), p38 factor, and cleavages of caspase-3 in pancreatic $\beta$-cells (33).

Protective effects of alpha-mangostin in hyperglycemiainduced cell dysfunction were further explained by its capability to protect various cells from apoptotic damage (33, 40, 41). Alpha-mangostin was shown to exert its anti-apoptotic effect in vitro, by attenuating the effects of high glucose in human umbilical vein endothelial cells (HUVEC). The effects of high glucose shown in the study includes the up-regulation of cleaved caspase- 3 and Bax, down-regulation of $\mathrm{BCl}-2$, elevation of ceramide levels, and the increase of acid sphingomyelinase activity (29). Further, alpha-mangostin restored the high glucose-induced apoptosis regulated by the H19/miR-140/HE4 regulatory axis in HUVEC cells (42). In rat primary hepatocytes, alpha-mangostin increased mitochondrial membrane potential, decreased total ROS, and decreased mitochondrial ROS levels, followed by reduced Caspase- 3 and Caspase- 9 activities compared with the control group (41).

In cells cultured under high glucose conditions, similar evidence is found on aldose-reductase (AR)-dependent factor in ROS generation, confirming $\mathrm{AR}$ as the primary cause for the pathogenesis of numerous diabetic complications (43). Among xanthones extracted from Garcinia mangostana, gamma-mangostin followed by alpha-mangostin showed strong inhibitory properties on aldose reductase (44).

Ryu et al. (34) demonstrated that prenylated xanthones exhibit $\alpha$-glucosidase inhibitory and antihyperglycemic activity in streptozotocin-induced diabetic rats, with gamma-mangostin being the most potent.

The activity of alpha-mangostin and gamma-mangostin in alleviating insulin resistance was explained in the primary cultures of human adipocytes. Alpha- and gamma-mangostin attenuated lipopolysaccharides (LPS) activation of the cJun $\mathrm{NH}(2)$-terminal kinase, extracellular signal-related kinase, mitogen-activated protein kinases (MAPK), and activator protein (AP)-1 activity. Gamma- mangostin was shown to be more potent in attenuating the MAPK signaling pathway. Gammamangostin also controlled the adiponectin gene expression and insulin-stimulated glucose uptake and PPAR- $\gamma(45)$.

Confirmation of long-term alpha-mangostin supplementation in type 2 diabetic rats was provided by Mekseepralard et al. (35) Alpha-mangostin given at $200 \mathrm{mg} / \mathrm{kg} \mathrm{BW/day} \mathrm{for} 40$ weeks resulted in a decreased level of $\mathrm{HbA} \mathrm{c}$, plasma cholesterol, fasting blood glucose, triglyceride, and followed by the increase serum insulin. Moreover, the long-term alpha-mangostin treated group demonstrated a better glucose tolerance pattern than the shortterm-supplemented group (8 weeks).

Moreover, alpha-mangostin also is shown to improve micro hemodynamic indices in type 2 diabetic rats $(46,47)$. Alphamangostin improves micro hemodynamic mean arterial pressure, serum insulin, plasma $\mathrm{HbA1c}$, blood cholesterol, triglyceride, and HOMA-IR index, compared with control diabetic rats (46). Further, $\alpha$-MG treated DM2 rats restore ocular blood flow by decreasing retinal MDA, AGEs, RAGE, TNF- $\alpha$, and VEGF (46). Interestingly, another study by the same group proves that $\alpha-M G$ is more effective than curcumin in improving MAP and retinal flow resistance in DM2 rats (37). Abdallah et al. (48) in his study, also confirmed that AGEs formation was inhibited by bioactive metabolites of Garcinia mangostana.

The protective effect of alpha-mangostin on diabetic nephropathy was reported in a diabetic rat model. Twelve-week after alpha-mangostin treatment, the diabetic kidney injury was reduced. The reduction of kidney injury was associated with a reduced level of acid sphingomyelinase and the down-regulation of ER stress-related protein expressions (49).

Mangosteen peel extract was also shown to exhibit a protective effect in the in vitro model of diabetic glomerulosclerosis, as the extract could promote cell growth in glucose-induced mesangial cells. It also significantly lowers the production of fibronectin and TGF- $\beta 1$ (50).

Limited clinical evidence is available on the efficacy of mangosteen in diabetic patients. However, few clinical trials have been performed on healthy obese patients with the additional observation on fasting plasma glucose and HOMA-IR (51-53). Mangosteen supplementation was shown to improve insulin sensitivity in a pilot clinical trial of 22 obese female patients. HOMA-IR was significantly improved in patients treated with behavioral therapy plus mangostin (HOMA-IR: $-53.22 \%$ ) vs. behavioral therapy only (HOMA-IR: $-15.23 \%$ ), with no notable adverse effects (53).

\section{Curcumin}

Curcumin is one of the natural products, among others, that received extensive attention for the prevention of progressivity of diabetic complications (54). Ample literature on curcumin shows its activity as an antidiabetic in animal models of diabetes with various doses and duration of research. Oral administration of multiple doses of curcumin, such as $80 \mathrm{mg} / \mathrm{kg} /$ day for 3 weeks (55) and 45 days (56); $60 \mathrm{mg} / \mathrm{kg} /$ day for 2 weeks (57); $100 \mathrm{mg} / \mathrm{kg} /$ day for 4 weeks, and 8 weeks (58) were able to prevent body weight loss, reduce blood glucose levels, and improve insulin sensitivity. Several possible mechanisms of the effects of curcumin in lowering blood glucose levels in diabetic animal models have been proposed, including the possibility that curcumin could attenuate plasma free fatty acids, tumor necrosis factor- $\alpha$ (TNF- $\alpha)$, nuclear factor-kappa B (NF-кB) activity, lipid peroxidation, and protein carbonyl. Also, curcumin decreased thiobarbituric acid reactive substances levels and the activity of sorbitol dehydrogenase $(59,60)$.

Recent studies showed that curcumin at a dose of $90 \mathrm{mg} / \mathrm{kg} /$ day plus insulin $1 \mathrm{U} /$ day vs. 4U/day given in streptozotocin-induced diabetic rats can decrease blood glucose levels, improve biomarkers of hepatorenal injury, attenuate lipid profile and hepatic antioxidants levels $(61,62)$. In addition, curcumin supplementation $(0.02 \%$, wt $/ \mathrm{wt})$ in $\mathrm{db} / \mathrm{db}$ mice for 6 weeks improved homeostasis model assessment of insulin resistance (HOMA-IR), glucose tolerance, and significantly lowered blood glucose levels and HbA1c levels. The mechanisms 
that cause a positive effect on blood glucose levels is due to curcumin's ability to increase hepatic glucokinase activity and to decrease glucose-6-phosphatase and phosphoenolpyruvate carboxykinase activity (63). El-Moselhy et al. (64) reported that curcumin $(80 \mathrm{mg} / \mathrm{kg} /$ day) administration for 75 days, obtained from Curcuma longa, in comparison with rosiglitazone (1 $\mathrm{mg} / \mathrm{kg} /$ day) in high-fat diet-induced type 2 diabetes mellitus in rats exhibits an anti-hyperglycemic effect and also improved insulin sensitivity, and this action is due to at least in part by curcumin's and rosiglitazone's anti-inflammatory activity. In addition to the inflammation process, oxidative stress also demonstrates an important role in terms of its relationship to cause type 2 diabetes mellitus. A study conducted by Kaur and Meena (65) demonstrated that the combination of curcumin, piperine, and quercetin is a natural source of antioxidants that can prevent oxidative stress caused by high-fat feeding and lowdose streptozotocin injection, at least in part through increased antioxidant activity. Curcumin has also been known to be able to improve insulin resistance in skeletal muscle through increased oxidation of fatty acids and glucose which is likely mediated through the LKB1-AMPK pathway. Curcumin reduced plasma glucose and plasma lipid dose-dependently with a dose of 150 $\mathrm{mg} / \mathrm{kgBW}$ showed the greatest effects compared with a dose of 50 $\mathrm{mg} / \mathrm{kgBW}$ in high-fat diet and low-dose STZ injection-induced diabetes rats (66).

Up till now, the use of curcumin in humans has not been recommended in certain conditions, for example, in pregnant or nursing mothers, children, or in patients with anemia or liver disease due to few studies done with those conditions. Panahi et al. (67) demonstrated that curcuminoids 500-1,000 $\mathrm{mg}$ /day plus piperine $5-10 \mathrm{mg}$ /day for 3 months decreased blood glucose levels significantly vs. a placebo in patients with type 2 diabetes. Also, curcuminoids also reduced C-peptide levels, HbAlc, TNF- $\alpha$, and alanine and aspartate aminotransferase levels with no adverse effects $(67,68)$. Renal dysfunction is one of the serious complications of diabetes mellitus and is characterized by progressive decline of eGFR, albuminuria, and hypertension (69). Currently, diabetic nephropathy is the leading initial trigger of chronic kidney disease complicating in terms of mortality and morbidity for diabetic individuals. Ample evidence demonstrated the multiple mechanisms by which curcumin may attenuate renal damage due to diabetes. It has been shown that curcumin increases clearance of BUN and creatinine $(58,70,71)$. Another study demonstrated that curcumin causes post-translational modification of $\mathrm{H} 3$ subtype histone and alteration of HSP-27 and p38 MAPK expression rate in kidney (70). Though curcumin could activate the p38MAPK-HSP25 pathway in mouse podocyte, it failed to modulate the possibility of albuminuria in STZ-induced diabetic mice (72). Clinical trials then assured the effect of curcumin on endstage renal disorders. They demonstrated that curcumin inhibits secretion of transforming growth factor- $\beta$ (TGF- $\beta$ ), urinary protein, and interleukin (IL)-8 (73). A randomized, double-blind, and placebo-controlled trial conducted by Chuengsamarn et al. on two hundred forty patients with prediabetes proved that the administration of curcumin extract for 9-months improved the beta-cell function of pancreas, with lower HOMA-IR and higher adiponectin affected significantly as compared to the placebo (73). Na et al. (74) continued their study of curcumin for diabetes mellitus from experimental animals to trials in humans, which included one-hundred patients who were overweight/obese with type 2 diabetes mellitus, randomly divided into two groups, a curcumin supplemented (300 $\mathrm{mg} /$ day) group and a placebo group for a period of 3 months. In the study, they proved that administration of curcumin supplementation significantly reduced fasting plasma glucose levels, insulin resistance, $\mathrm{HbA1c}$, serum triglycerides, and total free fatty acids as compared to the group receiving placebo (74).

\section{EFFECTS OF CINNAMON, MANGOSTEEN, AND CURCUMIN ON BLOOD PRESSURE}

\section{Cinnamon}

An animal study by Nyadjeu et al. (75) evaluates the antihypertensive property of Cinnamomum zeylanicum extract in three animal models of hypertensive and in isolated rat aortic in vitro study. Acute intravenous injection of the extract caused a significant drop in mean arterial blood pressure in anesthetized four groups of rats, such as normotensive Wistar rats, salt-loaded hypertensive, L-NAME hypertensive, and spontaneously hypertensive rats. Pretreatment with either atropine or propranolol dramatically masked the therapeutic effects of the extract, deducing its probable mechanism in interfering both sympathetic and cholinergic transmissions (75).

Moreover, possible active vasodilatation was restrained in the pretreatment of L-NAME rats, which might be predominantly mediated by an endothelial nitric oxide synthase pathway. In an isolated mouse aortic study, they found that extract antihypertensive mechanism was partly due to vasodilation via endothelial nitric oxide and potassium ATP channel activation in vascular smooth muscle (75).

One systematic review from Mousavi et al. (76) discussed nine trials that enrolled a total of 641 subjects. Cinnamon induced drop in SBP (Weighted Mean Differences (WMD): $-6.23 \mathrm{mmHg}$ and DBP (WMD: $-3.93 \mathrm{mmHg}$ ), which were optimally detected in trials using $<2 \mathrm{~g}$ cinnamon, more than 12 weeks length of experimentation, and $<50$ years-old participants. However, no non-linear association was concluded between study duration and cinnamon supplementation dosage in the aforementioned systolic blood pressure value. Although cinnamon shows potential effects in controlling hypertension, further studies are necessary to be conducted in order to confirm its reviewed therapeutic effectiveness (76).

\section{Mangosteen}

Healthy endothelium and blood vessels produce natural regulators of vascular tone and blood pressure. Endothelial cell dysfunction, as characterized by the impaired release of nitric oxide pathways, was found in hypertension (77).

A methanol extract of Garcinia mangostana fruit hulls showed a direct relaxant effect by increasing aortic nitric oxide in a MetS animal-isolated aorta (48). While in isolated rat aortic rings, $\gamma$-mangostin causes vasorelaxation via the NO-cGMP pathway. Also, $\gamma$-mangostin activates $\mathrm{K}^{+}$channels and inhibits the influx 
of extracellular calcium ion, which supports the use of mangostin as an antihypertensive agent (78).

Up to date, no clinical trials have been performed in hypertensive patients. However, studies on healthy volunteers and obese patients showed that the use of mangosteen extracts resulted in minimum changes in the subjects blood pressure $(51,53,79)$.

\section{Curcumin}

The increasing number of clinical trials proved that curcumin demonstrates cardioprotective efficacy, mainly due to its antihyperlipidemic and anti-atherosclerotic effects. A recent meta-analysis suggested that chronic supplementation of curcumin/turmeric could sustain a favorable impact on systolic blood pressure. Although the overall results did not show a dramatic decrease in systolic blood pressure and diastolic blood pressure after administration of curcumin, subgroup analysis showed that long-term administration of curcumin for more than 4 months was able to decrease systolic blood pressure but not diastolic blood pressure (80). These findings have been influenced by its low bioavailability during oral administration. More than half of the oral dose of curcumin will be excreted through feces, and only a small amount can be detected in plasma. This is because curcumin exhibits a poor solubility index, low intestinal permeability, and rapid first-pass biotransformation (81). The magnitude of reduction of systolic blood pressure was very slight following curcumin/turmeric supplementation; this is probably caused by curcumin, which can improve endothelial function. However, it has been proposed that the rate of ischemic heart disease and cerebrovascular accident were lowered by 7 and 10\%, respectively (82). Yet, its possible mechanism is not well comprehended. Yao et al. (83) revealed the possible mechanism of reducing blood pressure by curcumin, curcumin decreased angiotensin type-1 receptor formation in concentration, and the time-dependent manner in the vascular muscle cells, as well as decreasing specificity protein 1 (SP1) binding with the angiotensin 1 receptor promoter. The positive effects of curcumin on L-NAME induced endothelial dysfunction are closely related with suppression of oxidative stress, increased endothelial NOS activity, and rapid regeneration of glutathione to balance the status of redox system (84). Another study by Xia et al. (85) showed that curcumin administration significantly lowered the blood pressure of male albino rats in time- and dose-dependent manner. The authors proved that curcumin significantly increased RBC velocity, micro vessel diameter, dynamic vasomotion, and open capillaries number. Hodai et al. demonstrated that patients with type 2 diabetes supplemented with triple-daily for 10 weeks with either curcumin $(1,500 \mathrm{mg} /$ day $)$ or a placebo capsule showed no significant differences observed in the mean SBP and DBP within groups and between two groups. They also showed that there were no significant differences occurred in the body mass index between the two groups (86). Therefore, to provide curcumin as a blood pressure-lowering drug, further research is still required, especially in patients with hypertension and longer follow-up.

\section{EFFECTS OF CINNAMON, MANGOSTEEN, AND CURCUMIN ON LIPID PROFILE}

\section{Cinnamon}

In a hypercholesterolemic zebrafish model, cinnamon was discovered to slow down the atherosclerosis process by preventing glycation of apoA-1 and inhibiting activity of the cholesteryl ester transfer protein (87). Further, in the atherosclerotic animal model induced by dexamethasone, treatment with cinnamon extract improved glucocorticoidinduced dyslipidemia compared to the dexamethasone control group (88). Also, the aqueous cinnamon reduced the expressions of scavenger receptor class A and $\mathrm{T}$ cell receptor CD36, as well as uptake of acetyl-low density lipoprotein via regulation of ERK1/2 activity in macrophages (89).

Besides, cinnamon triggers the formation of PPAR- $\alpha$, PPAR- $\gamma$, and their target genes such as CD36 and GLUT4 membrane protein in adipocytes (25). Also, one of the active cinnamon ingredients, namely 2-methoxycinnamaldehyde, diminishes expression of vascular adhesion cell protein- 1 in tumor necrosis factor-alpha (TNF $\alpha$ )-activated HUVECs (43). Furthermore, the cinnamophilin derived in cinnamon extract was found to be an antagonistic ligand for thromboxane A2 receptor, inhibiting any platelet aggregation (90). Taken together, these results highlight the beneficial effects of cinnamon in atherosclerosis. Up to date, no clinical trials have been performed in specific patients with dyslipidemia to explore the beneficial effect of cinnamon in lipid profiles.

\section{Mangosteen}

Low-density lipoprotein (LDL) oxidation is an early event in atherogenesis. Therefore, the antioxidative effect of preventing oxidation of LDL has been the focus of atherosclerosis research (91). Alpha-mangostin acts as a radical species scavenger to keep the LDL from oxidative stress in vitro (92). Another study showed inhibition of $\alpha$-tocopherol consumption induced by LDL-oxidation by alpha-mangostin (93).

A study was done by Shibata et al. (94) and they reported that crude mangosteen extracts given for 17-weeks could inhibit the development of atherosclerosis in ApoE-/- mice. In mice treated with crude mangosteen extracts, total cholesterol and triglycerides reduced significantly, followed by a decreased hepatic fatty acid transporter and 3-hydroxy-3-methyl-glutarylcoenzyme A synthase (94). Ethanolic extract of mangosteen given at $800 \mathrm{mg} / \mathrm{kg} \mathrm{BW}$ in rats had also been shown to improve lipid profile in high cholesterol diet, as well as decrease the level of hydrogen peroxide, the expression of NF- $\mathrm{kB}$, inducible NOS pathway, HIF- $1 \alpha$, and maintain expression of endothelial NOS $(95,96)$. As a result, vasa vasorum angiogenesis, which occurs in atherosclerosis progression, also decreases (96).

In streptozotocin-induced rats, Taher et al. (32) showed that Garcinia mangostana extract did not only lower blood glucose levels but also reduced the levels of triglycerides (TG), LDL, total cholesterol (TC), very-low-density lipoprotein (VLDL), and increased HDL and total protein (TP).

In a small scale randomized controlled trial of 22 obese female patients, mangosteen extract $400 \mathrm{mg}$ once daily for 26 weeks was 
reported to increase HDL cholesterol $(58 \mathrm{mg} / \mathrm{dL}$ in the alphamangostin group vs. $49 \mathrm{mg} / \mathrm{dL}$ in control group). However, no improvement was found in other lipid profiles (TC, LDL-C, and triglycerides) (53). However, when Garcinia mangostana extract was administered in combination with Sphaerantus indicus flower heads extracts (also known as Meratrim) in clinical trials in overweight and obese subjects, significant reductions in TC $(-13.8 \%)$ and triglycerides $(-41.6 \%)$ were noted in the studies $(53,97)$.

\section{Curcumin}

Hypertriglyceridemia triggered by a high intake of fructoserich diets is a significant risk factor for cardiovascular disease. This may be caused by hepatic de novo lipogenesis, which then will increase the formation of free fatty acid rendering to hypertriglyceridemia. Excess triglycerides could be kept as lipid droplets in hepatocytes or secreted in the form of VLDL (98). The most common cause of liver damage that often coexists with MetS, such as diabetes and obesity, is the non-alcoholic liver disease. NAFLD often manifests as intracellular triglyceride accumulation complicating into inflammation (steatohepatitis), fibrosis, and eventually end-stage cirrhosis (99). If the simple steatosis is not treated early, it may progress to cirrhosis with ultimate failure of liver function and increases the risk for liver cancer pathogenesis.

Although vast ranges of lipid-lowering drugs are, dyslipidemia complications still exist. Curcumin has been studied for years for its benefits as an anti-inflammatory, antihyperlipidemic, and improved leptin resistance $(43,100,101)$. Li et al. (22) reported that curcumin improves condition with hypertriglyceridemia and suppresses hepatic protein tyrosine phosphatase $1 \mathrm{~B}$ formation to increase insulin sensitivity. A recent study has shown that curcumin could prevent hepatic steatosis and high-fructoseinduced hyperlipidaemia in male Wistar rats via suppression of protein expression of LXR- $\alpha$ and SREBP-1c in the liver as well as decreases the production of lipogenic enzymes, such as acetylCoA carboxylase or fatty acid synthase (23). A meta-analysis of seven trials, including a total of 649 subjects, conducted by Qin et al. (102) showed that administration of curcumin and turmeric could protect patients against the risk of cardiovascular disease by improving serum lipid levels, that is curcumin and turmeric could significantly decrease serum LDL-cholesterol and triglyceride levels as compared to those in control group. Curcumin is utilized as dietary adjunct to standard drugs. However, further research is needed to resolve its uncertain dosage and medication frequency.

The mechanism behind the hypolipidemic activity of curcumin and turmeric is partly because curcumin can increase PPAR- $\gamma$, suppressing the expression of the LDL-C receptor, and thereby reducing plasma LDL-C levels $(103,104)$. A recent study was performed in which curcumin was administered at a dose of $200 \mathrm{mg} /$ day and also a combination of phytosterols and curcumin at a dose of $2 \mathrm{~g} /$ day $-200 \mathrm{mg} /$ day, respectively, for 4 weeks to hypercholesterolemic individuals. The researchers found that the combination of phytosterols and curcumin supplementation could significantly lower TC, LDL-cholesterol, and ratio of total/HDL cholesterol as compared to that of single supplementation of phytosterol or curcumin. However, curcumin alone administration does not greatly reduce TC and LDL-cholesterol. They also stated that curcumin could potentiate the cholesterol-regulating effects toward phytosterol, suggestive for additive and synergistic effects (105).

\section{EFFECTS OF CINNAMON, MANGOSTEEN, AND CURCUMIN ON OBESITY}

\section{Cinnamon}

Kwan et al. (106) reported that cinnamon extract (CA) promoted multilocular brown fat phenotype in 3T3-L1 adipocytes. Moreover, it triggered expression of brown adipocytes markers but reduced expression of white adipocytes markers in the 3T3-L1 adipocytes. In this study, they also reported that cinnamon extract augmented brown adipocytes markers in the subcutaneous adipocytes isolated from diet-induced obesity (DIO) mice and $\mathrm{db} / \mathrm{db}$ mice. In addition, the oral administration of the extract enhanced UCP1 expression in the subcutaneous adipose tissue, as well as body weight reduction in the DIO group.

Another in vitro study reported that CA rapidly increases protein kinase A signaling, rate of expression of several thermogenic genes, and HSL-PLIN1 phosphorylation in the murine primary adipocytes. Suppression of protein kinase A or p38 MAPK enzymatic activity dramatically down-regulated the CA-induced thermogenesis. Furthermore, long-term CA treatment modulates reprogramming of metabolic pathways partially diminished in FGF21KO subtype adipocytes lineage. As a matter of fact, both acute and chronic effects of extract administration in isolated human adipose stem cells were observed, derived from different ethnicities, ages, and body mass index (BMI). Meanwhile, CA triggers thermogenesis and heat metabolism in mouse and human subcutaneous adipocytes, providing a mechanistic explanation for the anti-obesity results which further supports its potential metabolic benefits (107). In addition, the impact of dietary polyphenols (which are known to be rich in cinnamon) on the gut microbiota and intestinal barrier functions were also tested. C57BL/6J mice were fed with a high-fat diet (HFD) for 8 weeks treated with extract from cinnamon bark. At the genus level, Peptococcus were decreased in HFD mice treated with cinnamon, and the expression of several antimicrobial peptides and tight junctions proteins such as ANG4 (effective against gram-positive and gram-negative bacteria, Reg3y (effective against gram-positive bacteria), and Lyz1 (mostly effective against gram-positive bacteria) was increased in response to cinnamon supplementation, indicating an improvement of gut barrier function (108).

A clinical study determines the impact of a 4-month treatment with dietary herbal supplements, such as chromium, cinnamon, and carnosine, toward either moderately obese or overweight pre-diabetic subjects. A 4-month treatment with the dietary supplement decreased FPG compared to placebo, without detectable significant changes in HbAlc. They did not find any changes in HOMA-IR markers, levels of serum insulin, lipid profile, and inflammatory markers among treatment groups. Although they did not find any alterations in weight and 
nutrient intakes between two groups, the proportion of fat mass diminished within the supplemented group compared to placebo one. A higher FPG concentration and milder inflammatory status benefited most from the supplementation (109).

In a 16-week double-blind randomized control trial, more than 100 individuals with MetS were divided into two groups, which were given cinnamon $3 \mathrm{~g} /$ day or wheat flour $2.5 \mathrm{~g} /$ day. Fasting plasma glucose, HbAlc level, waist circumference, and BMI was decreased in the cinnamon-treated group compared to the placebo one. Other parameters such as waist-hip ratio, total serum cholesterol, blood pressure, serum triglycerides, LDL cholesterol, and HDL cholesterol significantly improved (110). However, cinnamon did not change gastric emptying parameters, postprandial lipemia, glycemia, and appetite responses to highfat breakfast in 9 healthy, young subjects supplemented with one dose of 3 grams powdered cinnamon. No significant effect of cinnamon treatment was observed on sensations of hunger, desire to eat and fullness (111).

\section{Mangosteen}

Alpha-mangostin displayed its anti-obesity property in vitro by inducing apoptosis in 3T3 L1 (preadipocyte cells) as well as inhibiting fatty acid synthase at $20 \mu \mathrm{M}$ (112). Moreover, alphamangostin was found to inhibit intracellular fat accumulation and prevent adipocytes maturation $(112,113)$.

Alpha-mangostin is highly distributed in the liver and fat in vivo, which makes it plausible to consider alpha-mangostin as anti-obesity $(114,115)$. Several mice or rat models of high-fat diet-induced obesity demonstrated the effect of mangostin in reducing body weight and retroperitoneal fat mass accumulation $(41,116,117)$.

Chronic low-grade inflammation also contributed to adipogenesis $(118,119)$. Xanthones from mangosteen have been shown to prevent lipopolysaccharide (LPS)-mediated inflammatory response in vitro by modulating TNF- $\alpha$, IL-6, interferon $\gamma$-inducible protein-10 (112). Chen et al. studied the anti-inflammatory mechanism of alpha- and gamma-mangostin in RAW 264.7 cells stimulated by lipopolysaccharide. The results showed that alpha- and gamma-mangostins significantly inhibited nitric oxide (NO) and $\mathrm{PGE}_{2}$. However, further analysis proved that the inhibitory activities of both xanthones are not due to direct inhibition of iNOS enzyme activity (120). A recent study proposed a mechanism by which alpha-mangostin successfully modulated LPS-stimulated IEC- 6 cell inflammation using a genome-wide examination of control, LPS-stimulated, and alpha-mangostin-pretreated cells. The study showed that $\alpha$ MG pretreatment reduced LPS-induced expressions of NLRP3, caspase 1, interleukin (IL)-18, and IL-1 $\beta$ (121).

Moreover, alpha-mangostin, and gamma-mangostin were able to prevent the activation of MAPK, NF-KB, and AP1, which can induce the transcription of pro-inflammatory cytokines released in obesity subjects (122). Shen et al. (123) found that alphamangostin exhibits potent activity in reducing NF-kB mediated inflammation and inhibiting Nrf2 promoter activity.

The previous study indicated antagonistic crosstalk between NF- $\kappa$ B and SIRT1 in the inflammatory signaling pathway. SIRT1 activation inhibits NF- $\mathrm{B}$ signaling and suppresses inflammation.
SIRT1 suppresses NF- $\mathrm{B}$ signaling by deacetylating the p65 subunit of NF- $\kappa$ B complex (124-126). While in an in vitro study using the U937 cell line and human monocytes, alpha-mangostin was proven to inhibit p65 acetylation and down-regulate its downstream products, COX-2, iNOS via SIRT1 activation (127). In high-fat diet-induced obese mice, alpha-mangostin reduced body weight by upregulating hepatic AMPK, SIRT1, and PPAR$\gamma$ (117).

The effect of mangosteen juice on biomarkers of inflammation in 122 who were obese was evaluated after 8-week of supplementation, and the researchers found that in the highest dose evaluated ( $9 \mathrm{oz}$ twice daily), improvements on hs-CRP and F2 isoprostane occurred. However, no significant changes in BMI and body fat percentages occurred (51).

The excessive oxidative stress in adipose tissues has also been shown to be linked with the pathogenesis of obesity (128). Mangosteen, given in the form of a single-dose functional beverage of Garcinia mangostana to healthy male and female subjects, increased plasma antioxidants and enhanced endogenous antioxidant activity (129).

Alteration in leptin expressions are also known to be important in obesity (130). Leptin is an adipocyte-secreted hormone that regulates appetite. An increase in leptin concentration will result in an anorexic effect (131). Yet, in wild type animals and in most human subjects, leptin concentrations increase by a HFD (132). In vitro study showed that alpha-mangostin increased mRNA expressions of leptin in 3T3-L1 adipocyte cells. However, Abuzaid et al. (133) reported that ethanolic extract of mangosteen pericarp significantly reduced resistin and leptin concentrations and reduced body weights in Wistar rats given HFDs.

Recent studies highlighted the role of gut microorganisms in the pathogenesis of obesity. Epidemiological studies in obesity subjects found reduced abundance in Bacteroidetes and an increase in Firmicutes phylum (134). Further, studies suggested that microbiome might stimulate reprogramming of gene expression in the gut $(135,136)$. Up to date, no study proved the efficacy of alpha-mangostin in improving dysbiosis in obesity. However, a recent study showed that alpha-mangostin altered intestinal microbiome, promoted dysbiosis and exacerbated colonic inflammation and injury in chemically-induced colitis in mice (137). Gutierrez-Orozco et al. (137) reported that alphamangostin significantly disrupts intestinal microbiomes, by reducing the amount of Firmicutes and increasing the abundance of Proteobacteria. The dysbiosis might be due to the inefficient absorption of alpha-mangostin that leads to high amounts of the compound transit in the colon and interacts with gut microbiota.

Clinical trials of mangosteen supplementation in subjects who are obese have been performed using several doses and in a variety of duration. A randomized controlled trial was conducted in 60 subjects who are obese with BMI between 30 and 40 $\mathrm{kg} / \mathrm{m}^{2}$, receiving either herbal extract from Spaeranthus indicus and Garcinia mangostana or a placebo for 8 weeks. Herbal extracts resulted in a reduction in BMI of $1.61 \mathrm{~kg} / \mathrm{m}^{2}$ as well as the reduction in waist circumference of $5.44 \mathrm{~cm}$. An increase in adiponectin concentrations was also observed in the herbal group (52). In a randomized controlled trial of 22 subjects 
of obese female (BMI $\geq 30 \mathrm{~kg} / \mathrm{m}^{2}$ with a bodyweight of $<$ $135 \mathrm{~kg}$ ), mangosteen $400 \mathrm{mg}$ once daily as a supplement to diet and physical activity for 26-week resulted in a weight loss of $-4.5 \mathrm{~kg}$ in mangostin group vs. $-1.42 \mathrm{~kg}$ in the placebo group. However, no significant difference was found regarding waist circumference and body composition vs. control (53).

Garcinia mangostana extracts given as herbal blend with extract of Sphaeranthus indicus (known as Meratrim) has been evaluated in several clinical trials of overweight and obese participants. In two identical clinical trials, 100 subjects with a BMI of $30-40 \mathrm{~kg} / \mathrm{m}^{2}$ were given $400 \mathrm{mg}$ of herbal blend twice daily or placebo for 8 weeks. At the end of the study, significant reductions in body weight $(-5.2 \mathrm{kgs}), \mathrm{BMI}\left(-2.2 \mathrm{~kg} / \mathrm{m}^{2}\right)$, waist $(-11.9 \mathrm{~cm})$, and hip circumference $(-6.3 \mathrm{~cm})$ in herbal blend vs. the placebo occurred. The changes were followed by an increase in serum adiponectin concentration $(52,138)$.

The same combination was also studied in a placebocontrolled clinical trial in 60 overweight patients. Meratrim in $400 \mathrm{mg}$ capsules was given to 60 participants with a BMI of $28.3 \mathrm{~kg} / \mathrm{m}^{2}$ twice daily for 16 weeks. Large-scale body weight reduction ( 5.09 vs. $1.1 \mathrm{~kg}$ )), waist $(9.97 \mathrm{vs.} 3.71 \mathrm{~cm})$, hip size (10.38 vs. $5.11 \mathrm{~cm})$, and BMI $\left(1.91 \mathrm{vs.} 0.43 \mathrm{~kg} / \mathrm{m}^{2}\right)$ in the Meratrim group compared to the placebo one (97).

Taken together, anti-inflammatory and antioxidative properties of mangostin might be beneficial in modifying obesity and its related disorders.

\section{Curcumin}

An ample of evidence suggests that specific dietary components found in spices, for instance, curcumin, may exert a beneficial effect on metabolism and possess anti-obesity and antiinflammatory activities (139-141). Obesity is one of the risk factors of cardiovascular and kidney disease (142). Liu et al. (109) investigated the effects of curcumin on the prevention and treatment of obesity-related glomerulopathy. They explored its possible signal transduction pathway in vitro and in vivo experiments. They found that curcumin upregulated mRNA and protein expression of podocyte-associated molecules via leptin induction, like nephrin, podoplanin, podocins, and podocalyxin. They also proved that curcumin significantly reduced the body weight, Lee's index, abdominal fat index, urinary protein excretion, and average glomerular diameter and significantly upregulated the mRNA and protein expressions of the above podocyte-associated molecules in obesity-related glomerulopathy mice. The authors proved that the mechanisms of curcumin inhibit the obesity-related glomerulopathy was at least in part due to curcumin's ability to regress the high expression of Wnt2b, Wnt1, Wnt6, and $\beta$-catenin signaling on podocytes (109).

A recent study also demonstrated that supplementing HFD mice with curcumin and piperine could accelerate the caloric restriction-induced loss of total body fat. This combination is an effective intervention at suppressing high-fat diet-induced inflammation (143). A systematic review and meta-analysis of randomized controlled trials among patients with MetS and related disorders given by curcumin were assessed to find whether curcumin administration could reduce BMI and weight. A total of 1,163 studies were identified with total participants being 1,646 patients. The results of this systematic review and meta-analysis were that curcumin intake could be suggested as a useful supplement to be used for the management of the MetS. Curcumin intake significantly reduced BMI, weight, waist circumference, and increased adiponectin levels. However, the authors found a non-dramatic effect of curcumin intake on the hip ratio (144).

Curcumin is a polyphenol with an aromatic ring and one or more hydroxyl groups. It is now known that polyphenols exhibit biological effects following chemical modification carried out by gut microbiota. Actually, enzymes released by gut microbiota will perform deglycosylation, dehydroxylation, and a demethylation of polyphenols resulting in small catabolic products, which are easily absorbed during intestinal transit (145). Recently, several enteric bacteria have been identified that are capable of modifying curcumin, namely Escherichia coli, Blautia spp., Escherichia fergusonii, Bifidobacteria longum, Bifidobacteria pseudocatenulaum, Lactobacillus acidophilus, and Lactobacillus casei. All of these gut microbiotas can metabolize curcumin into two derivatives, demethylcurcumin and bisdemethylcurcumin (146). In fact, after oral administration of curcumin and metabolism of curcumin in the liver, curcumin in the intestine will change the ratio between pathogenic bacteria and beneficial bacteria by increasing the abundance of Bifidobacteria and Lactobacilli and reducing the loads of Prevotellaceae, Coriobacterales, Enterobacteria, and Enterococci (147).

Gut dysbiosis is defined as an alteration in the composition of gut microbiota and this alteration can occur due to exposure of various environmental factors including food, drugs such as antimicrobial agents, toxins, pathogens, and increased stress (148). Several studies have shown that a tight interaction exists between the gut microbiota dysbiosis and diabetes mellitus and obesity $(149,150)$. The alteration of composition of gut microbiota can also be induced by consumption of highfat food, at least in part by increasing pathogen microbiota such as Rikenellaceae and decreasing Ruminococcaceae (151). Shen et al. (152) demonstrated that the administration of curcumin by gavage at a dose of $100 \mathrm{mg} / \mathrm{kgBW}$ for 15 days in C57BL/6 mice significantly decreased the abundance of Prevotellaceae while increased the abundance of Bacteroidaceae and Rikenellaceae. Prevotella species is a gram-negative bacteria that is very commonly found in the gut of patients with colorectal cancer (153). Moreover, Bereswill et al. (154) also demonstrated the beneficial effects of resveratrol, curcumin, and simvastatin in a murine model of hyper-acute Th1-type ileitis following orally infected by Toxoplasma gondii. Resveratrol, curcumin, and simvastatin equally could ameliorate acute small intestine inflammation by upregulating anti-inflammatory cytokines, IL10 in ileum, mesenteric lymph nodes, and spleen and also increase the abundance of anti-inflammatory lactobacilli and bifidobacteria. All of the three compounds could maintain intestinal barrier function.

\section{FUTURE DIRECTIONS}

In summary, a considerable amount of studies was carried out on the effects of cinnamon, mangosteen, and curcumin on MetS. The 
TABLE 1 | Summary of pharmacological activity of cinnamon, mangosteen, and curcumin in target organ.

\begin{tabular}{|c|c|c|c|c|}
\hline Plant name & $\begin{array}{l}\text { Extract/compound } \\
\text { used }\end{array}$ & $\begin{array}{l}\text { Cells/ } \\
\text { organ studied }\end{array}$ & Pharmacological activity & References \\
\hline \multicolumn{5}{|l|}{ Cinnamon } \\
\hline Cinnamon zeylanicum & $\begin{array}{l}\text { Methanol extracts of } \\
\text { bark }\end{array}$ & intestine & Competitive, reversible inhibition on $\alpha$-glucosidase enzyme (Wistar rats) & $(155)$ \\
\hline Cinnamon zeylanicum & Cinnamaldehyde & $\begin{array}{l}\text { Skeletal muscle } \\
\text { Liver tissue }\end{array}$ & $\begin{array}{l}\text { Restore GLUT4 protein content } \\
\text { Improvement in altered enzyme activities of pyruvate kinase and } \\
\text { phosphoenolpyruvate carboxykinase (Wistar rats) }\end{array}$ & $(156)$ \\
\hline Cinnamon cassia & $\begin{array}{l}\text { Ethanol extract of } \\
\text { bark }\end{array}$ & $\begin{array}{l}\text { Adipose tissue and } \\
\text { liver }\end{array}$ & Promote lipid accumulation (db/db mice) & (26) \\
\hline Cinnamon tamala & $\begin{array}{l}\text { Ethanol extract of } \\
\text { bark }\end{array}$ & Blood and pancreas & $\begin{array}{l}\text { Improved insulin concentration } \\
\text { (db/db mice) }\end{array}$ & $(26)$ \\
\hline Cinnamon cassia & Water extract & Adipocyte cell line & $\begin{array}{l}\text { Increased protein level of PPAR- } \gamma \\
\text { (3T3-L1) }\end{array}$ & $(25)$ \\
\hline Cinnamon zeylanicum & Water extracts & $\begin{array}{l}\text { In vitro (BSA-Glucose } \\
\text { assay) }\end{array}$ & Inhibit the formation of advanced glycation end-products & $(157)$ \\
\hline \multicolumn{5}{|l|}{ Mangosteen } \\
\hline \multirow[t]{12}{*}{ Garcinia mangostana } & Ethanolic extract & Plasma & $\begin{array}{l}\downarrow \text { Blood glucose (Wistar rats) } \\
\downarrow \text { Total cholesterol and hydrogen peroxide (Wistar rats, Sprague Dawley } \\
\text { rats, ApoE deficient mice) }\end{array}$ & $(32,94-96)$ \\
\hline & Alpha mangostin & Plasma & $\begin{array}{l}\downarrow \text { HbA1c, Total cholesterol, LDL, TG, VLDL, fasting blood glucose } \\
\text { (Sprague Dawley rats) } \\
\uparrow \text { HDL and total protein (Sprague Dawley rats) } \\
\uparrow \text { Insulin, } \\
\downarrow \text { HOMA IR (Sprague Dawley rats) } \\
\downarrow \text { Hs-CRP and F2-isoprostane } \\
\uparrow \text { Adiponectin (in human volunteers) } \\
\uparrow \text { Leptin (Wistar rats) }\end{array}$ & $\begin{array}{c}(32,35,46,47,51- \\
53,97,133)\end{array}$ \\
\hline & Alpha mangostin & & Negligible effect of blood pressure (obese female patients, albino mice) & $(53-55)$ \\
\hline & Alpha-mangostin & Pancreatic islet & $\begin{array}{l}\uparrow \Sigma \text { of beta cells (Sprague Dawley rats) } \\
\uparrow \text { Expression of insulin receptor and Pdx1 (INS-1 cells) } \\
\uparrow \text { Insulin secretion (Sprague Dawley rats) } \\
\uparrow \text { Phosphorylation of PI3K/Akt \& ERK (INS-1 cells) } \\
\downarrow \text { Phosphorylation of JNK (INS-1 cells) }\end{array}$ & $(32,33)$ \\
\hline & Alpha mangostin & Endothelial cells & $\begin{array}{l}\text { Anti-apoptotic (INS-1 cells, HUVEC cells, Sprague Dawley rats) } \\
\text { Regulates H19/miR/HE4 (HUVEC cells) }\end{array}$ & $(33,40-42)$ \\
\hline & Alpha mangostin & Hepatocytes & $\begin{array}{l}\uparrow \text { Mitochondrial membrane potential (Sprague Dawley rats) } \\
\downarrow \text { Total ROS and mitochondrial ROS (Sprague Dawley rats) } \\
\downarrow \text { Caspase-3 and Caspase-9 (Sprague Dawley rats) } \\
\downarrow \text { Hepatic fatty acid transporter (ApoE deficient mice) } \\
\downarrow \text { HMG-CoA synthase (ApoE deficient mice) } \\
\downarrow \text { NF-KB, iNOS, HIF- } 1 \alpha \text { (Wistar rats) }\end{array}$ & $(41,94-96)$ \\
\hline & $\begin{array}{l}\text { Alpha- and gamma- } \\
\text { mangostin }\end{array}$ & Adipocytes & $\begin{array}{l}\downarrow \text { JNK, MAPK, AP1 } \\
\uparrow \text { PPAR- } \gamma \text { (primary culture of human adipocyte) } \\
\uparrow \text { Apoptosis in preadipocytes cells Inhibit fatty acid synthase (3T3-L1) } \\
\downarrow \text { NLRP3, Caspase } 1, I L-18, I L-1 \beta \text { (3T3-L1 cells, primary culture of } \\
\text { human adipocytes) } \\
\downarrow \text { NF-kB (primary culture of human adipocytes) Inhibiting Nrf2 activity } \\
\text { (3T3-L1 cells) } \\
\uparrow \text { AMPK, SIRT1, PPAR- } \gamma \text { (C57BL mice) } \\
\uparrow \text { Leptin (3T3-L1 cells) }\end{array}$ & $\begin{array}{c}(45,112,113,117 \\
121,123,132)\end{array}$ \\
\hline & Alpha- mangostin & Retina & $\begin{array}{l}\downarrow \text { MDA, AGEs, RAGE, TNF- } \alpha, \text { VEGF (Sprague Dawley rats) } \\
\downarrow \text { Retinal flow resistance (Sprague Dawley rats) }\end{array}$ & $(46,47)$ \\
\hline & Alpha- mangostin & Mesangial cells & $\begin{array}{l}\downarrow \text { Fibronectin (SV40 MES } 13 \text { cells) } \\
\downarrow \text { TGF- } \beta 1 \text { (SV40 MES } 13 \text { cells) }\end{array}$ & $(50)$ \\
\hline & Alpha-mangostin & Aorta & $\uparrow$ NO (Wistar rats) Vasorelaxation via NO-cGMP pathway (Wistar rats) & $(78)$ \\
\hline & Gamma- mangostin & Aorta & $\begin{array}{l}\text { Activates } \mathrm{K}^{+} \text {channels (Wistar rats) } \\
\text { Inhibits influx of } \mathrm{Ca}^{2+} \text { (Wistar rats) }\end{array}$ & (78) \\
\hline & Alpha-mangostin & Gut & $\uparrow$ Gut dysbiosis (C3H, Balb/c, Nude FoxN1nu and C57BL/6J mice) & $(137)$ \\
\hline
\end{tabular}


TABLE 1 | Continued

\begin{tabular}{|c|c|c|c|c|}
\hline Plant name & $\begin{array}{l}\text { Extract/compound } \\
\text { used }\end{array}$ & $\begin{array}{l}\text { Cells/ } \\
\text { organ studied }\end{array}$ & Pharmacological activity & References \\
\hline \multicolumn{5}{|l|}{ Curcumin } \\
\hline Turmeric & Extract & Plasma & $\begin{array}{l}\text { Reduced blood glucose, } \mathrm{Hb} \text {, and glycosylated hemoglobin levels } \\
\text { (Alloxan-induced Albino rats) }\end{array}$ & (55) \\
\hline Curcumin & $\begin{array}{l}\text { Curcumin } \\
\text { compound }\end{array}$ & Cerebellum & $\begin{array}{l}\text { Increase gene expression of Ach, Glut3, Muscarinic M1, M3, alpha7 } \\
\text { nicotinic acetylcholine, \& insulin receptor (Streptozotocin-induced male } \\
\text { Wistar rats) }\end{array}$ & $(57)$ \\
\hline Curcumin & $\begin{array}{l}\text { Curcumin } \\
\text { compound }\end{array}$ & Kidneys & $\begin{array}{l}\text { Increase creatinine clearance, reduce blood urea nitrogen, activities of } \\
\text { PKC- } \alpha \text {, and PKC- } \beta 1 \text { and phosphorylated of ERK } 1 / 2 \\
\text { (streptozotocin-induced male Sprague Dawley rats) }\end{array}$ & $(58)$ \\
\hline Curcumin & $\begin{array}{l}\text { Curcumin- } \\
\text { supplemented } \\
\text { yogurt }\end{array}$ & $\begin{array}{l}\text { Adipose tissue, } \\
\text { muscular tissue, } \\
\text { plasma, urine }\end{array}$ & $\begin{array}{l}\text { Reduce urine urea \& glucose, proteinuria, serum triacylglycerol, \& } \\
\text { activities of aspartate \& alanine aminotransferases. } \\
\text { Increase hepatic glycogen (streptozotocin-induced diabetic rats) }\end{array}$ & (62) \\
\hline Turmeric & Curcumin & Kidney & $\begin{array}{l}\text { Down-regulate mRNA \& protein expression of Wnt1, Wnt2b, Wnt6, \& } \\
\text { Beta catenin \& up-regulate phosphorylation of beta-catenin protein in } \\
\text { podocytes \& renal tissues (immortalized mouse podocyte cell line \& } \\
\text { high-fat diet-induced C57BL/6J mice) }\end{array}$ & (109) \\
\hline Turmeric & Curcumin & $\begin{array}{l}\text { Adipose tissue and } \\
\text { plasma }\end{array}$ & $\begin{array}{l}\text { Decrease IL-1 } 1 \beta \text {, IL-6 } \\
\text { Increase loss of body fat high-fat diet-induced C57BL/6J mice) }\end{array}$ & $(143)$ \\
\hline Curcumin & Curcumin & Small intestine & $\begin{array}{l}\text { Increase IL-10, lactobacilli, bifidobacteria } \\
\text { Decrease IL-23p 19, IFN- } \gamma, \text { TNF- } \alpha, \text { IL-6, MCP-1 (C57BL/10ScSn mice) }\end{array}$ & (154) \\
\hline Curcumin & $\begin{array}{l}\text { Combination extract } \\
\text { of curcumin: } \\
\text { piperine: quercetin in } \\
\text { a ratio } 94: 1: 5)\end{array}$ & Skeletal muscle & $\begin{array}{l}\text { Increase AMPK, CD36, carnitine palmitoyltransferase } 1 \\
\text { Decrease pyruvate dehydrogenase 4, phosphorylated glycogen } \\
\text { synthase (High-fat diet and low-dose streptozotocin-induced albino } \\
\text { female wistar rats) }\end{array}$ & $(66)$ \\
\hline
\end{tabular}

$\uparrow$ Increased; $\downarrow$ Decreased.

similarity of the results of the three extracts on MetS was based on their antioxidant, anti-inflammatory, and anti-apoptosis effects.

Overall, based on in vitro and in vivo studies, all three extracts, cinnamon, mangosteen, and curcumin exhibit excellent organtargeted effects on MetS, as summarized in Table 1. While based on the available data on clinical trials that have been conducted, the studies were performed only on selected components of MetS such as hyperglycemia, diabetes, dyslipidemia, or obesity.

We also note that the three compounds show variable outcomes in different components of MetS. Cinnamon demonstrated better outcomes in hypertension, while mangosteen in obesity and curcumin on patients with hyperglycemia.

In order to be certain on the efficacy and safety of the three medicinal plants, well-designed clinical trials, with representative sample sizes, are still needed. Up to date, results from clinical trial data available are inconsistent, not to mention the limited number of studies are available on patients with MetS. Further, the number of patients recruited was also confined. We also note the heterogeneity in the results of clinical trials. The results' heterogeneity might be due to the various sources of the extracts which leads to the non-uniformity of ingredients used in the studies. The level of purity in the active compounds used also varied. Previous studies confirmed several findings of heavy metals or pesticides contaminations from contaminated soil or production process (158).

Limited bioavailability is among the challenges which make dose findings in human trials difficult. Unlike active compounds of cinnamon that have relatively good bioavailability, mangosteen and curcumin are poorly absorbed $(16,159,160)$. Moreover, animal studies revealed that limited bioavailability of alphamangostin might lead to high amounts of compound in the gut, which resulted in the dysregulation of gut microbiomes (137, 161). Studies revealed that the interactions between gut microbiota and herbal compounds can be attributed to absorbable active small molecules and changed gut microbiota and its secretion (162), but at present, no studies informed the role of cinnamon, curcumin and mangosteen in this issue.

Limited and conflicting data from clinical trials in MetS, non-uniformity of quality and sources, and limited long-term safety results, among other things, are still preventing recommendations of these compounds for use in MetS.

Based on the current review, we saw promising results with a clear mechanism of actions of cinnamon, mangosteen, and curcumin. To confirm their efficacy in patients, further welldesigned clinical studies need to be done to explore the effects on standardized effects with a large number of MetS patients. Further, long-term human studies are also needed, considering the possibility of long-term use of the drugs in MetS.

\section{AUTHOR CONTRIBUTIONS}

WA, ML, and VS contributed manuscript writing. WA revised and finalized the manuscript. 


\section{FUNDING}

We thanked Direktorat Jendral Pendidikan Tinggi Republic Indonesia for the funding support. This fund was received for open access publication fees.

\section{REFERENCES}

1. Kassi E, Pervanidou P, Kaltsas G, Chrousos G. Metabolic syndrome: definitions and controversies. BMC Med. (2011) 9:48. doi: 10.1186/1741-7015-9-48

2. Ranasinghe P, Jayawardana R, Galappaththy P, Constantine GR, de Vas Gunawardana N, Katulanda P. Efficacy and safety of 'true' cinnamon (Cinnamomum zeylanicum) as a pharmaceutical agent in diabetes: a systematic review and meta-analysis. Diab Med. (2012) 29:1480-92. doi: 10.1111/j.1464-5491.2012.03718.x

3. Herningtyas EH, Ng TS. Prevalence and distribution of metabolic syndrome and its components among provinces and ethnic groups in Indonesia. BMC Public Health. (2019) 19:377. doi: 10.1186/s12889-019-6711-7

4. Mottillo S, Filion KB, Genest J, Joseph L, Pilote L, Poirier P, et al. The metabolic syndrome and cardiovascular risk a systematic review and meta-analysis. J Am Coll Cardiol. (2010) 56:1113-32. doi: 10.1016/j.jacc.2010.05.034

5. Grundy SM. Drug therapy of the metabolic syndrome: minimizing the emerging crisis in polypharmacy. Nat Rev Drug Discov. (2006) 5:295-309. doi: $10.1038 / \mathrm{nrd} 2005$

6. Pengpid S, Peltzer K. Utilization of traditional and complementary medicine in Indonesia: results of a national survey in 2014-15. Complement Ther Clin Pract. (2018) 33:156-63. doi: 10.1016/j.ctcp.2018.10.006

7. Woerdenbag HJ, Kayser O. Jamu: Indonesian traditional herbal medicine towards rational phytopharmacological use. J Herb Med. (2014) 4:51-73. doi: 10.1016/j.hermed.2014.01.002

8. Rochlani Y, Pothineni NV, Kovelamudi S, Mehta JL. Metabolic syndrome: pathophysiology, management, and modulation by natural compounds. Ther Adv Cardiovasc Dis. (2017) 11:215-25. doi: 10.1177/1753944717711379

9. von Rintelen K, Arida E, Häuser C. A review of biodiversity-related issues and challenges in megadiverse Indonesia and other Southeast Asian countries. Res Ideas Outcomes. (2017) 3:e20860. doi: 10.3897/rio.3.e20860

10. Rao PV, Gan SH. Cinnamon: a multifaceted medicinal plant. Evid Based Complement Alternat Med. (2014) 2014:642932. doi: 10.1155/2014/642942

11. Kumar S, Kumari R, Mishra S. Pharmacological properties and their medicinal uses of Cinnamomum: a review. J Pharm Pharmacol. (2019) 71:1735-61. doi: 10.1111/jphp.13173

12. Makimori RY, Endo EH, Makimori JW, Zanqueta EB, Ueda-Nakamura T, Leimann FV, et al. Preparation, characterization and antidermatophytic activity of free- and microencapsulated cinnamon essential oil. J Mycol Med. 2020:100933. doi: 10.1016/j.mycmed.2020.100933

13. Obolskiy D, Pischel I, Siriwatanametanon N, Heinrich M. Garcinia mangostana L.: a phytochemical and pharmacological review. Phytother Res. (2009) 23:1047-65. doi: 10.1002/ptr.2730

14. Aizat WM, Jamil IN, Ahmad-Hashim FH, Noor NM. Recent updates on metabolite composition and medicinal benefits of mangosteen plant. Peer J. (2019) 7:e6324. doi: 10.7717/peerj.6324

15. Wang MH, Zhang KJ, Gu QL, Bi XL, Wang JX. Pharmacology of mangostins and their derivatives: a comprehensive review. Chin J Nat Med. (2017) 15:81-93. doi: 10.1016/S1875-5364(17)30024-9

16. Gutierrez-Orozco F, Failla ML. Biological activities and bioavailability of mangosteen xanthones: a critical review of the current evidence. Nutrients. (2013) 5:3163-83. doi: 10.3390/nu5083163

17. Muchtaridi M, Suryani D, Qosim W, Saptarini N. Quantitative analysis of $\alpha$-mangostin in mangosteen (Garcinia mangostana L.) Pericarp extract from four district of west java by HPLC method. Int J Pharm Pharm Sci. (2016) 8:232-6. Available online at: https://innovareacademics.in/ journals/index.php/ijpps/article/view/12297/6296
ACKNOWLEDGMENTS

We would like to acknowledge English language editing and proofreading were provided by Andrea Laurentius and Enago Academic Editing Service (www.enago.com).

18. Nahar L, Sarker SD, Turner AB. A review on synthetic and natural steroid dimers: 1997-2006. Curr Med Chem. (2007) 14:1349-70. doi: 10.2174/092986707780597880

19. Li R, Xiang C, Ye M, Li HF, Zhang X, Guo DA. Qualitative and quantitative analysis of curcuminoids in herbal medicines derived from Curcuma species. Food Chem. (2011) 126:1890-5. doi: 10.1016/j.foodchem.2010.12.014

20. Inoue K, Nomura C, Ito S, Nagatsu A, Hino T, Oka H. Purification of curcumin, demethoxycurcumin, and bisdemethoxycurcumin by high-speed countercurrent chromatography. J Agric Food Chem. (2008) 56:9328-36. doi: 10.1021/jf801815n

21. Anand P, Kunnumakkara AB, Newman RA, Aggarwal BB. Bioavailability of curcumin: problems and promises. Mol Pharm. (2007) 4:807-18. doi: 10.1021/mp700113r

22. Li JM, Li YC, Kong LD, Hu QH. Curcumin inhibits hepatic protein-tyrosine phosphatase $1 \mathrm{~B}$ and prevents hypertriglyceridemia and hepatic steatosis in fructose-fed rats. Hepatology. (2010) 51:1555-66. doi: 10.1002/hep.23524

23. Maithilikarpagaselvi N, Sridhar MG, Swaminathan RP, Sripradha R, Badhe B. Curcumin inhibits hyperlipidemia and hepatic fat accumulation in high-fructose-fed male Wistar rats. Pharm Biol. (2016) 54:2857-63. doi: 10.1080/13880209.2016.1187179

24. Cao H, Polansky MM, Anderson RA. Cinnamon extract and polyphenols affect the expression of tristetraprolin, insulin receptor, and glucose transporter 4 in mouse 3T3-L1 adipocytes. Arch Biochem Biophys. (2007) 459:214-22. doi: 10.1016/j.abb.2006.12.034

25. Sheng $X$, Zhang $Y$, Gong Z, Huang C, Zang YQ. Improved Insulin resistance and lipid metabolism by cinnamon extract through activation of peroxisome proliferator-activated receptors. PPAR Res. (2008) 2008:581348. doi: $10.1155 / 2008 / 581348$

26. Chen L, Sun P, Wang T, Chen K, Jia Q, Wang H, et al. Diverse mechanisms of antidiabetic effects of the different procyanidin oligomer types of two different cinnamon species on db/db mice. J Agric Food Chem. (2012) 60:9144-50. doi: 10.1021/jf3024535

27. Bandara T, Uluwaduge I, Jansz E. Bioactivity of cinnamon with special emphasis on diabetes mellitus: a review. Int J Food Sci Nutr. (2012) 63:380-6. doi: 10.3109/09637486.2011.627849

28. Medagama AB. The glycaemic outcomes of Cinnamon, a review of the experimental evidence and clinical trials. Nutr J. (2015) 14:108. doi: 10.1186/s12937-015-0098-9

29. Akilen R, Tsiami A, Devendra D, Robinson N. Glycated haemoglobin and blood pressure-lowering effect of cinnamon in multi-ethnic Type 2 diabetic patients in the UK: a randomized, placebo-controlled, double-blind clinical trial. Diab Med. (2010) 27:1159-67. doi: 10.1111/j.1464-5491.2010. 03079.x

30. Manaf A, Tjandrawinata RR, Malinda D. Insulin sensitizer in prediabetes: a clinical study with DLBS3233, a combined bioactive fraction of Cinnamomum burmanii and Lagerstroemia speciosa. Drug Des Dev Ther. (2016) 10:1279-89. doi: 10.2147/DDDT.S97568

31. Talaei B, Amouzegar A, Sahranavard S, Hedayati M, Mirmiran P, Azizi F. Effects of cinnamon consumption on glycemic indicators, advanced glycation end products, and antioxidant status in type 2 diabetic patients. Nutrients. (2017) 9:991. doi: 10.3390/nu9090991

32. Taher M, Tg Zakaria TMFS, Susanti D, Zakaria ZA. Hypoglycemic activity of ethanolic extract of Garcinia mangostana Linn. in normoglycaemic and streptozotocin-induced diabetic rats. BMC Complement Altern Med. (2016) 16:135. doi: 10.1186/s12906-016-1118-9

33. Lee D, Kim YM, Jung K, Chin YW, Kang KS. Alpha-mangostin improves insulin secretion and protects INS-1 cells from streptozotocin-induced damage. Int J Mol Sci. (2018) 19:1484. doi: 10.3390/ijms19051484 
34. Ryu HW, Cho JK, Curtis-Long MJ, Yuk HJ, Kim YS, Jung S, et al. $\alpha$-Glucosidase inhibition and antihyperglycemic activity of prenylated xanthones from Garcinia mangostana. Phytochemistry. (2011) 72:2148-54. doi: 10.1016/j.phytochem.2011.08.007

35. Mekseepralard C, Areebambud C, Suksamrarn S, Jariyapongskul A. Effects of long-term alpha-mangostin supplementation on hyperglycemia and insulin resistance in type 2 diabetic rats induced by high fat diet and low dose streptozotocin. J Med Assoc Thai. (2015) 98:S23-30. Available online at: http://www.jmatonline.com/index.php/jmat/article/view/6887\#

36. Lenzen S. The mechanisms of alloxan- and streptozotocin-induced diabetes. Diabetologia. (2008) 51:216-26. doi: 10.1007/s00125-007-0886-7

37. Al-Awar A, Kupai K, Veszelka M, Szucs G, Attieh Z, Murlasits Z, et al. Experimental diabetes mellitus in different animal models. J Diab Res. (2016) 2016:9051426. doi: 10.1155/2016/9051426

38. Panchal SK, Brown L. Rodent models for metabolic syndrome research. $J$ Biomed Biotechnol. (2011) 2011:351982. doi: 10.1155/2011/351982

39. Wong SK, Chin KY, Suhaimi FH, Fairus A, Ima-Nirwana S. Animal models of metabolic syndrome: a review. Nutr Metab. (2016) 13:65. doi: 10.1186/s12986-016-0123-9

40. Luo Y, Lei M. $\alpha$-Mangostin protects against high-glucose induced apoptosis of human umbilical vein endothelial cells. Biosci Rep. (2017) 37:BSR20170779. doi: 10.1042/BSR20170779

41. Tsai SY, Chung PC, Owaga EE, Tsai IJ, Wang PY, Tsai JI, et al. Alpha-mangostin from mangosteen (Garcinia mangostana Linn.) pericarp extract reduces high fat-diet induced hepatic steatosis in rats by regulating mitochondria function and apoptosis. Nutr Metab. (2016) 13:88. doi: 10.1186/s12986-016-0148-0

42. Luo Y, Fang Z, Ling Y, Luo W. LncRNA-H19 acts as a ceRNA to regulate HE4 expression by sponging miR-140 in human umbilical vein endothelial cells under hyperglycemia with or without $\alpha$-Mangostin. Biomed Pharmacother. (2019) 118:109256. doi: 10.1016/j.biopha.2019.109256

43. Tang W, Martin KA, Hwa J. Aldose reductase, oxidative stress, and diabetic mellitus. Front Pharmacol. (2012) 3:87. doi: 10.3389/fphar.2012.00087

44. Soda M, Endo S, Matsunaga T, Zhao HT, El-Kabbani O, Iinuma M, et al. Inhibition of human aldose reductase-like protein (AKR1B10) by $\alpha$-and $\gamma$ mangostins, major components of pericarps of mangosteen. Biol Pharm Bull. (2012) 35:2075-80. doi: 10.1248/bpb.b12-00538

45. Bumrungpert A, Kalpravidh RW, Chitchumroonchokchai C, Chuang CC, West T, Kennedy A, et al. Xanthones from mangosteen prevent lipopolysaccharide-mediated inflammation and insulin resistance in primary cultures of human adipocytes. J Nutr. (2009) 139:1185-91. doi: $10.3945 /$ jn.109.106617

46. Jariyapongskul A, Areebambud C, Suksamrarn S, Mekseepralard C. Alphamangostin attenuation of hyperglycemia-induced ocular hypoperfusion and blood retinal barrier leakage in the early stage of type 2 diabetes rats. BioMed Res Int. (2015) 2015:785826. doi: 10.1155/2015/785826

47. Jariyapongskul A, Areebambud C, Hideyuki N. Microhemodynamic indices to evaluate the effectiveness of herbal medicine in diabetes: a comparison between alpha-mangostin and curcumin in the retina of type 2 diabetic rats. Clin Hemorheol Microcirc. (2018) 69:471-80. doi: 10.3233/CH-170345

48. Abdallah HM, El-Bassossy H, Mohamed GA, El-Halawany AM, Alshali KZ, Banjar ZM. Phenolics from Garcinia mangostana inhibit advanced glycation endproducts formation: effect on amadori products, cross-linked structures and protein thiols. Molecules. (2016) 21:251. doi: $10.3390 /$ molecules 21020251

49. Liu T, Duan W, Nizigiyimana P, Gao L, Liao Z, Xu B, et al. Alpha-mangostin attenuates diabetic nephropathy in association with suppression of acid sphingomyelinase and endoplasmic reticulum stress. Biochem Biophys Res Comm. (2018) 496:394-400. doi: 10.1016/j.bbrc.2018.01.040

50. Widowati W, Laksmitawati DR, Wargasetia TL, Afifah E, Amalia A, Arinta Y, et al. Mangosteen peel extract (Garcinia mangostana L.) as protective agent in glucose-induced mesangial cell as in vitro model of diabetic glomerulosclerosis. Iran J Basic Med Sci. (2018) 21:972-7. doi: 10.22038/IJBMS.2018.29349.7094

51. Jay U, Betsy S, Marilyn B, Vijay S. Evaluation of Mangosteen juice blend on biomarkers of inflammation in obese subjects: a pilot, dose finding study. Nutr J. (2009) 8:48. doi: 10.1186/1475-2891-8-48
52. Stern J, Peerson J, Mishra A, Sadasiva Rao M, Rajeswari K. Efficacy and tolerability of a novel herbal formulation for weight management. Obesity. (2013) 21:921-7. doi: 10.1002/oby.20211

53. Watanabe M, Gangitano E, Francomano D, Addessi E, Toscano R, Costantini $\mathrm{D}$, et al. Mangosteen extract shows a potent insulin sensitizing effect in obese female patients: a prospective randomized controlled pilot study. Nutrients. (2018) 10:586. doi: 10.3390/nu10050586

54. Jiang CS, Liang LF, Guo YW. Natural products possessing protein tyrosine phosphatase 1B (PTP1B) inhibitory activity found in the last decades. Acta Pharmacol Sin. (2012) 33:1217-45. doi: 10.1038/aps.2012.90

55. Arun N, Nalini N. Efficacy of turmeric on blood sugar and polyol pathway in diabetic albino rats. Plant Foods Hum Nutr. (2002) 57:41-52. doi: 10.1023/A:1013106527829

56. Pari L, Murugan P. Influence of tetrahydrocurcumin on tail tendon collagen contents and its properties in rats with streptozotocin-nicotinamideinduced type 2 diabetes. Fundam Clin Pharmacol. (2007) 21:665-71. doi: 10.1111/j.1472-8206.2007.00542.x

57. Peeyush KT, Gireesh G, Jobin M, Paulose C. Neuroprotective role of curcumin in the cerebellum of streptozotocin-induced diabetic rats. Life Sci. (2009) 85:704-10. doi: 10.1016/j.lfs.2009.09.012

58. Soetikno V, Watanabe K, Sari FR, Harima M, Thandavarayan RA, Veeraveedu PT, et al. Curcumin attenuates diabetic nephropathy by inhibiting PKC- $\alpha$ and PKC- $\beta 1$ activity in streptozotocininduced type I diabetic rats. Mol Nutr Food Res. (2011) 55:1655-65. doi: 10.1002/mnfr.201100080

59. El-Azab MF, Attia FM, El-Mowafy AM. Novel role of curcumin combined with bone marrow transplantation in reversing experimental diabetes: effects on pancreatic islet regeneration, oxidative stress, and inflammatory cytokines. Eur J Pharmacol. (2011) 658:41-8. doi: 10.1016/j.ejphar.2011.02.010

60. Jain SK, Rains J, Croad J, Larson B, Jones K. Curcumin supplementation lowers TNF- $\alpha$, IL-6, IL- 8 , and MCP-1 secretion in high glucose-treated cultured monocytes and blood levels of TNF- $\alpha$, IL-6, MCP-1, glucose, and glycosylated hemoglobin in diabetic rats. Antioxid Redox Signal. (2009) 11:241-9. doi: 10.1089/ars.2008.2140

61. Gutierres VO, Assis RP, Arcaro CA, Oliveira JO, Lima TFO, Beretta ALRZ, et al. Curcumin improves the effect of a reduced insulin dose on glycemic control and oxidative stress in streptozotocin-diabetic rats. Phytother Res. (2019) 33:976-88. doi: 10.1002/ptr.6291

62. Gutierres VO, Pinheiro CM, Assis RP, Vendramini RC, Pepato MT, Brunetti IL. Curcumin-supplemented yoghurt improves physiological and biochemical markers of experimental diabetes. Br J Nutr. (2012) 108:440-8. doi: $10.1017 /$ S0007114511005769

63. Seo K-I, Choi MS, Jung UJ, Kim HJ, Yeo J, Jeon SM, et al. Effect of curcumin supplementation on blood glucose, plasma insulin, and glucose homeostasis related enzyme activities in diabetic db/db mice. Mol Nutr Food Res. (2008) 52:995-1004. doi: 10.1002/mnfr.200700184

64. El-Moselhy MA, Taye A, Sharkawi SS, El-Sisi SFI, Ahmed AF. The antihyperglycemic effect of curcumin in a high fat diet fed rats. Role of TNF- $\alpha$ and free fatty acids. Food Chem Toxicol. (2011) 49:1129-40. doi: 10.1016/j.fct.2011.02.004

65. Kaur G, Meena C. Amelioration of obesity, glucose intolerance, and oxidative stress in high-fat diet and low-dose streptozotocin-induced diabetic rats by combination consisting of "curcumin with piperine and quercetin". ISRN Pharmacol. (2012) 2012:957283. doi: 10.5402/2012/957283

66. Na LX, Zhang YL, Li Y, Liu LY, Li R, Kong T, et al. Curcumin improves insulin resistance in skeletal muscle of rats. Nutr Metab Cardiovasc Dis. (2011) 21:526-33. doi: 10.1016/j.numecd.2009.11.009

67. Panahi Y, Khalili N, Sahebi E, Namazi S, Atkin SL, Majeed $\mathrm{M}$, et al. Curcuminoids plus piperine modulate adipokines in type 2 diabetes mellitus. Curr Clin Pharmacol. (2017) 12:253-8. doi: 10.2174/1574884713666180104095641

68. Panahi Y, Khalili N, Sahebi E, Namazi S, Simental-Mendía LE, Majeed $\mathrm{M}$, et al. Effects of curcuminoids plus piperine on glycemic, hepatic and inflammatory biomarkers in patients with type 2 diabetes mellitus: a randomized double-blind placebo-controlled trial. Drug Res. (2018) 68:4039. doi: 10.1055/s-0044-101752 
69. Maric-Bilkan C. Obesity and diabetic kidney disease. Med Clin. (2013) 97:59-74. doi: 10.1016/j.mcna.2012.10.010

70. Tikoo K, Meena R, Kabra D, Gaikwad A. Change in post-translational modifications of histone $\mathrm{H} 3$, heat-shock protein-27 and MAP kinase p38 expression by curcumin in streptozotocin-induced type I diabetic nephropathy. $\mathrm{Br} J$ Pharmacol. (2008) 153:1225-31. doi: 10.1038/sj.bjp.0707666

71. Sharma S, Kulkarni SK, Chopra K. Curcumin, the active principle of turmeric (Curcuma longa), ameliorates diabetic nephropathy in rats. Clin Exp Pharmacol Physiol. (2006) 33:940-5. doi: 10.1111/j.1440-1681.2006.04468.x

72. Ma J, Phillips L, Wang Y, Dai T, LaPage J, Natarajan R, et al. Curcumin activates the p38 MAPK-HSP25 pathway in vitro but fails to attenuate diabetic nephropathy in DBA2J mice despite urinary clearance documented by HPLC. BMC Complement Altern Med. (2010) 10:1-17. doi: 10.1186/1472-6882-10-67

73. Khajehdehi P, Pakfetrat M, Javidnia K, Azad F, Malekmakan L, Nasab MH, et al. Oral supplementation of turmeric attenuates proteinuria, transforming growth factor- $\beta$ and interleukin- 8 levels in patients with overt type 2 diabetic nephropathy: a randomized, double-blind and placebo-controlled study. Scand J Urol Nephrol. (2011) 45:365-70. doi: 10.3109/00365599.2011.585622

74. Na LX, Li Y, Pan HZ, Zhou XL, Sun DJ, Meng M, et al. Curcuminoids exert glucose-lowering effect in type 2 diabetes by decreasing serum free fatty acids: a double-blind, placebo-controlled trial. Mol Nutr Food Res. (2013) 57:1569-77. doi: 10.1002/mnfr.201200131

75. Nyadjeu P, Dongmo A, Nguelefack TB, Kamanyi A. Antihypertensive and vasorelaxant effects of Cinnamomum zeylanicum stem bark aqueous extract in rats. J Compl Integr Med. (2011) 8:1-18. doi: 10.2202/1553-3840.1490

76. Mousavi SM, Karimi E, Hajishafiee M, Milajerdi A, Amini MR, Esmaillzadeh A. Anti-hypertensive effects of cinnamon supplementation in adults: a systematic review and dose-response meta-analysis of randomized controlled trials. Crit Rev Food Sci Nutr. (2019) 16:1-11. doi: 10.1080/10408398.2019.1678012

77. Saxena T, Ali AO, Saxena M. Pathophysiology of essential hypertension: an update. Expert Rev Cardiovasc Ther. (2018) 16:879-87. doi: 10.1080/14779072.2018.1540301

78. Tep-Areenan P, Suksamrarn S. Mechanisms of vasorelaxation to gammamangostin in the rat aorta. J Med Assoc Thai. (2012) 95(Suppl. 12):S638. Available online at: http://www.jmatonline.com/index.php/jmat/article/ view/2389

79. Chitchumroonchokchai C, Riedl KM, Suksumrarn S, Clinton SK, Kinghorn $\mathrm{AD}$, Failla ML. Xanthones in mangosteen juice are absorbed and partially conjugated by healthy adults. $J$ Nutr. (2012) 142:675-80. doi: $10.3945 /$ jn.111.156992

80. Hadi A, Pourmasoumi M, Ghaedi E, Sahebkar A. The effect of Curcumin/Turmeric on blood pressure modulation: a systematic review and meta-analysis. Pharmacol Res. (2019) 150:104505. doi: 10.1016/j.phrs.2019.104505

81. Siviero A, Gallo E, Maggini V, Gori L, Mugelli A, Firenzuoli F, et al. Curcumin, a golden spice with a low bioavailability. J Herb Med. (2015) 5:57-70. doi: 10.1016/j.hermed.2015.03.001

82. Collaboration PS. Age-specific relevance of usual blood pressure to vascular mortality: a meta-analysis of individual data for one million adults in 61 prospective studies. Lancet. (2002) 360:1903-13. doi: 10.1016/S0140-6736(02)11911-8

83. Yao Y, Wang W, Li M, Ren H, Chen C, Wang J, et al. Curcumin exerts its antihypertensive effect by down-regulating the AT 1 receptor in vascular smooth muscle cells. Sci Rep. (2016) 6:1-8. doi: 10.1038/srep25579

84. Nakmareong S, Kukongviriyapan U, Pakdeechote P, Kukongviriyapan V, Kongyingyoes B, Donpunha W, et al. Tetrahydrocurcumin alleviates hypertension, aortic stiffening and oxidative stress in rats with nitric oxide deficiency. Hypertens Res. (2012) 35:418-25. doi: 10.1038/hr.2011.180

85. Xia J, Wang H, Zhang QM, Zheng Z, Han ZM. The therapeutic effect of curcumin in male albino rats and its putative mechanisms on cerebral microvascular flow. Brain Res. (2016) 1642:131-5. doi: 10.1016/j.brainres.2016.03.022

86. Hodai H, Adibian M, Sohrab G. Effects of curcumin supplementation on BMI and blood pressure in patients with type 2 diabetes. Endocrine Abstracts. (2016) 43:OC51. doi: 10.1530/endoabs.43.OC51
87. Jin S, Cho KH. Water extracts of cinnamon and clove exhibits potent inhibition of protein glycation and anti-atherosclerotic activity in vitro and in vivo hypolipidemic activity in zebrafish. Food Chemical Toxicol. (2011) 49:1521-9. doi: 10.1016/j.fct.2011.03.043

88. Nayak IN, Chinta R, Jetti R. Anti-atherosclerotic potential of aqueous extract of Cinnamomum zeylanicum bark against glucocorticoid induced atherosclerosis in wistar rats. J Clin Diagn Res. (2017) 11:FC19-23. doi: $10.7860 / J C D R / 2017 / 23910.9864$

89. Kang H, Park SH, Yun JM, Nam TG, Kim YE, Kim DO, et al. Effect of cinnamon water extract on monocyte-to-macrophage differentiation and scavenger receptor activity. BMC complement Altern Med. (2014) 14:90. doi: 10.1186/1472-6882-14-90

90. Yu SM, Wu TS, Teng CM. Pharmacological characterization of cinnamophilin, a novel dual inhibitor of thromboxane synthase and thromboxane A2 receptor. Br J Pharmacol. (1994) 111:906-12. doi: 10.1111/j.1476-5381.1994.tb14824.x

91. Stocker R, Keaney JF Jr. Role of oxidative modifications in atherosclerosis. Physiol Rev. (2004) 84:1381-478. doi: 10.1152/physrev.00047.2003

92. Williams P, Ongsakul M, Proudfoot J, Croft K, Beilin L. Mangostin inhibits the oxidative modification of human low density lipoprotein. Free Rad Res. (1995) 23:175-84. doi: 10.3109/10715769509064030

93. Mahabusarakam W, Proudfoot J, Taylor W, Croft K. Inhibition of lipoprotein oxidation by prenylated xanthones derived from mangostin. Free Rad Res. (2000) 33:643-59. doi: 10.1080/10715760000301161

94. Shibata MA, Harada-Shiba M, Shibata E, Tosa H, Matoba Y, Hamaoka H, et al. Crude $\alpha$-Mangostin suppresses the development of atherosclerotic lesions in apoe-deficient mice by a possible M2 macrophage-mediated mechanism. Int J Mol Sci. (2019) 20:1722. doi: 10.3390/ijms20071722

95. Wihastuti TA, Widodo MA, Heriansyah T, Sari NAK. Study of the inhibition effect of ethanolic extract of mangosteen pericarp on atherogenesis in hypercholesterolemic rat. Asian Pac J Trop Dis. (2015) 5:830-4. doi: 10.1016/S2222-1808(15)60940-9

96. Wihastuti TA, Sargowo D, Tjokroprawiro A, Permatasari N, Widodo MA, Soeharto S. Vasa vasorum anti-angiogenesis through $\mathrm{H}_{2} \mathrm{O}_{2}$, HIF$1 \alpha$, NF- $\kappa \mathrm{B}$, and iNOS inhibition by mangosteen pericarp ethanolic extract (Garcinia mangostana Linn) in hypercholesterol-diet-given Rattus norvegicus Wistar strain. Vasc Health Risk Manag. (2014) 10:523-31. doi: 10.2147/VHRM.S61736

97. Kudiganti V, Kodur RR, Kodur SR, Halemane M, Deep DK. Efficacy and tolerability of Meratrim for weight management: a randomized, doubleblind, placebo-controlled study in healthy overweight human subjects. Lipids Health Dis. (2016) 15:136. doi: 10.1186/s12944-016-0306-4

98. Brunzell JD. Clinical practice. Hypertriglyceridemia. New Engl J Med. (2007) 357:1009-17. doi: 10.1056/NEJMcp070061

99. Neuschwander-Tetri BA, Caldwell SH. Nonalcoholic steatohepatitis: summary of an AASLD Single Topic Conference. Hepatology. (2003) 37:1202-19. doi: 10.1053/jhep.2003.50193

100. Shapiro H, Bruck R. Therapeutic potential of curcumin in non-alcoholic steatohepatitis. Nutr Res Rev. (2005) 18:212-21. doi: 10.1079/NRR2005106

101. Jang EM, Choi MS, Jung UJ, Kim MJ, Kim HJ, Jeon SM, et al. Beneficial effects of curcumin on hyperlipidemia and insulin resistance in high-fat-fed hamsters. Metabolism. (2008) 57:1576-83. doi: 10.1016/j.metabol.2008.06.014

102. Qin S, Huang L, Gong J, Shen S, Huang J, Ren H, et al. Efficacy and safety of turmeric and curcumin in lowering blood lipid levels in patients with cardiovascular risk factors: a meta-analysis of randomized controlled trials. Nutr J. (2017) 16:68. doi: 10.1186/s12937-017-0293-y

103. Nishiyama T, Mae T, Kishida H, Tsukagawa M, Mimaki Y, Kuroda M, et al. Curcuminoids and sesquiterpenoids in turmeric (Curcuma longa L.) suppress an increase in blood glucose level in type 2 diabetic KK-Ay mice. $J$ Agric Food Chem. (2005) 53:959-63. doi: 10.1021/jf0483873

104. Kang Q, Chen A. Curcumin suppresses expression of low-density lipoprotein (LDL) receptor, leading to the inhibition of LDL-induced activation of hepatic stellate cells. Br J Pharmacol. (2009) 157:1354-67. doi: $10.1111 /$ j.1476-5381.2009.00261.x

105. Ferguson JJ, Stojanovski E, MacDonald-Wicks L, Garg ML. Curcumin potentiates cholesterol-lowering effects of phytosterols in hypercholesterolaemic individuals. A randomised controlled 
trial. Metabolism. (2018) 82:22-35. doi: 10.1016/j.metabol.2017. 12.009

106. Kwan HY, Wu J, Su T, Chao XJ, Liu B, Fu X, et al. Cinnamon induces browning in subcutaneous adipocytes. Sci Rep. (2017) 7:2447. doi: 10.1038/s41598-017-02263-5

107. Jiang J, Emont MP, Jun H, Qiao X, Liao J, Kim DI, et al. Cinnamaldehyde induces fat cell-autonomous thermogenesis and metabolic reprogramming. Metabolism. (2017) 77:58-64. doi: 10.1016/j.metabol.2017.08.006

108. Van Hul M, Geurts L, Plovier H, Druart C, Everard A, Ståhlman M, et al. Reduced obesity, diabetes, and steatosis upon cinnamon and grape pomace are associated with changes in gut microbiota and markers of gut barrier. Am J Physiol Endocrinol Metab. (2018) 314:E334-52. doi: 10.1152/ajpendo.00107.2017

109. Liu Y, Cotillard A, Vatier C, Bastard JP, Fellahi S, Stévant M, et al. A dietary supplement containing cinnamon, chromium and carnosine decreases fasting plasma glucose and increases lean mass in overweight or obese prediabetic subjects: a randomized, placebo-controlled trial. PLoS ONE. (2015) 10:e0138646. doi: 10.1145/2818302

110. Jain SG, Puri S, Misra A, Gulati S, Mani K. Effect of oral cinnamon intervention on metabolic profile and body composition of Asian Indians with metabolic syndrome: a randomized double-blind control trial. Lipids Health Dis. (2017) 16:113. doi: 10.1186/s12944-017-0504-8

111. Markey O, McClean CM, Medlow P, Davison GW, Trinick TR, Duly E, et al. Effect of cinnamon on gastric emptying, arterial stiffness, postprandial lipemia, glycemia, and appetite responses to high-fat breakfast. Cardiovasc Diabetol. (2011) 10:78. doi: 10.1186/1475-2840-10-78

112. Quan X, Wang Y, Ma X, Liang Y, Tian W, Ma Q, et al. $\alpha-$ Mangostin induces apoptosis and suppresses differentiation of 3T3-L1 cells via inhibiting fatty acid synthase. PLoS One. (2012) 7:e33376. doi: 10.1371/journal.pone.0033376

113. Taher M, Amiroudine M, Ali MZ, Zakaria T, Syafiq TMF, Susanti D, et al. $\alpha$ Mangostin improves glucose uptake and inhibits adipocytes differentiation in 3T3-L1 cells via PPAR $\gamma$, GLUT4, and leptin expressions. Evid Based Complement Alternat Med. (2015) 2015:740238. doi: 10.1155/2015/740238

114. Petiwala SM, Li G, Ramaiya A, Kumar A, Gill RK, Saksena S, et al. Pharmacokinetic characterization of mangosteen (Garcinia mangostana) fruit extract standardized to $\alpha$-mangostin in C57BL/6 mice. Nutrition Res. (2014) 34:336-45. doi: 10.1016/j.nutres.2014.03.002

115. Li L, Han AR, Kinghorn AD, Frye RF, Derendorf H, Butterweck V. Pharmacokinetic properties of pure xanthones in comparison to a mangosteen fruit extract in rats. Planta Med. (2013) 79:646-53. doi: $10.1055 / \mathrm{s}-0032-1328543$

116. Kim HM, Kim YM, Huh JH, Lee ES, Kwon MH, Lee BR, et al. $\alpha$-Mangostin ameliorates hepatic steatosis and insulin resistance by inhibition CC chemokine receptor 2. PLoS ONE. (2017) 12:e0179204. doi: 10.1371/journal.pone.0179204

117. Choi YH, Bae JK, Chae HS, Kim YM, Sreymom Y, Han L, et al. $\alpha$-Mangostin regulates hepatic steatosis and obesity through SirT1-AMPK and PPAR $\gamma$ pathways in high-fat diet-induced obese mice. J Agric Food Chem. (2015) 63:8399-406. doi: 10.1021/acs.jafc.5b01637

118. Ellulu MS, Patimah I, Khaza'ai H, Rahmat A, Abed Y. Obesity and inflammation: the linking mechanism and the complications. Arch Med Sci. (2017) 13:851. doi: 10.5114/aoms.2016.58928

119. Castro A, Macedo-de la Concha L, Pantoja-Meléndez C. Low-grade inflammation and its relation to obesity and chronic degenerative diseases. Rev Méd Hosp Gen Méx. (2017) 80:101-5. doi: 10.1016/j.hgmx.2016.06.011

120. Chen LG, Yang LL, Wang CC. Anti-inflammatory activity of mangostins from Garcinia mangostana. Food Chem Toxicol. (2008) 46:688-93. doi: 10.1016/j.fct.2007.09.096

121. Yin P, Zou W, Li J, Jin N, Gao Q, Liu F. Using high-throughput sequencing to explore the anti-inflammatory effects of $\alpha$-mangostin. Sci Rep. (2019) 9:15626. doi: 10.1038/s41598-019-52036-5

122. Bumrungpert A, Kalpravidh RW, Chuang CC, Overman A, Martinez K, Kennedy A, et al. Xanthones from mangosteen inhibit inflammation in human macrophages and in human adipocytes exposed to macrophageconditioned media. J Nutr. (2010) 140:842-7. doi: 10.3945/jn.109.120022

123. Shen Q, Chitchumroonchokchai C, Thomas JL, Gushchina LV, DiSilvestro D, Failla ML, et al. Adipocyte reporter assays: application for identification of anti-inflammatory and antioxidant properties of mangosteen xanthones. Mol Nutr Food Res. (2014) 58:239-47. doi: 10.1002/mnfr.201300181

124. Schug TT, Li X. Sirtuin 1 in lipid metabolism and obesity. Ann Med. (2011) 43:198-211. doi: 10.3109/07853890.2010.547211

125. Gillum MP, Kotas ME, Erion DM, Kursawe R, Chatterjee P, Nead KT, et al. SirT1 regulates adipose tissue inflammation. Diabetes. (2011) 60:3235-45. doi: $10.2337 / \mathrm{db} 11-0616$

126. Kauppinen A, Suuronen T, Ojala J, Kaarniranta K, Salminen A. Antagonistic crosstalk between NF-KB and SIRT1 in the regulation of inflammation and metabolic disorders. Cell Signal. (2013) 25:1939-48. doi: 10.1016/j.cellsig.2013.06.007

127. Franceschelli S, Pesce M, Ferrone A, Patruno A, Pasqualone L, Carlucci G, et al. A novel biological role of $\alpha$-mangostin in modulating inflammatory response through the activation of SIRT-1 signaling pathway. J Cell Physiol. (2016) 231:2439-51. doi: 10.1002/jcp.25348

128. Manna P, Jain SK. Obesity, oxidative stress, adipose tissue dysfunction, and the associated health risks: causes and therapeutic strategies. Metab Syndr Relat Disord. (2015) 13:423-44. doi: 10.1089/met.2015.0095

129. Xie Z, Sintara M, Chang T, Ou B. Functional beverage of Garcinia mangostana (mangosteen) enhances plasma antioxidant capacity in healthy adults. Food Sci Nutr. (2015) 3:32-8. doi: 10.1002/fsn3.187

130. Oussaada SM, van Galen KA, Cooiman MI, Kleinendorst L, Hazebroek EJ, van Haelst MM, et al. The pathogenesis of obesity. Metabolism. (2019) 92:26-36. doi: 10.1016/j.metabol.2018.12.012

131. Gruzdeva O, Borodkina D, Uchasova E, Dyleva Y, Barbarash O. Leptin resistance: underlying mechanisms and diagnosis. Diabetes Metab Syndr Obes. (2019) 12:191-8. doi: 10.2147/DMSO.S182406

132. Engin A. Diet-Induced obesity and the mechanism of leptin resistance. $A d v$ Exp Med Biol. (2017) 960:381-97. doi: 10.1007/978-3-319-48382-5_16

133. Abuzaid AS, Iskandar EY, Kurniati NF, Adnyana IK. Prevention of obesity and development of metabolic syndrome by mangosteen (Garcinia mangostana L.) pericarp ethanolic extract in male wistar rats fed with high-fat diet. Int J Pharm Pharmaceutic Sci. (2016) 8:1-7. doi: $10.18311 /$ jnr/2017/11051

134. Sun L, Ma L, Ma Y, Zhang F, Zhao C, Nie Y. Insights into the role of gut microbiota in obesity: pathogenesis, mechanisms, and therapeutic perspectives. Protein Cell. (2018) 9:397-403. doi: 10.1007/s13238-018-0546-3

135. Ley RE, Turnbaugh PJ, Klein S, Gordon JI. Microbial ecology: human gut microbes associated with obesity. Nature. (2006) 444:1022-3. doi: $10.1038 / 4441022 a$

136. Qin Y, Roberts JD, Grimm SA, Lih FB, Deterding LJ, Li R, et al. An obesity-associated gut microbiome reprograms the intestinal epigenome and leads to altered colonic gene expression. Genome Biol. (2018) 19:7. doi: 10.1186/s13059-018-1389-1

137. Gutierrez-Orozco F, Thomas-Ahner JM, Galley JD, Bailey MT, Clinton SK, Lesinski GB, et al. Intestinal microbial dysbiosis and colonic epithelial cell hyperproliferation by dietary $\alpha$-mangostin is independent of mouse strain. Nutrients. (2015) 7:764-84. doi: 10.3390/nu7020764

138. Sengupta K, Mishra AT, Rao MK, Sarma KV, Krishnaraju AV, Trimurtulu G. Efficacy and tolerability of a novel herbal formulation for weight management in obese subjects: a randomized double blind placebo controlled clinical study. Lipids Health Dis. (2012) 11:122. doi: 10.1186/1476-511X-11-122

139. He Y, Yue Y, Zheng X, Zhang K, Chen S, Du Z. Curcumin, inflammation, and chronic diseases: how are they linked? Molecules. (2015) 20:9183-213. doi: 10.3390/molecules20059183

140. Shao W, Yu Z, Chiang Y, Yang Y, Chai T, Foltz W, et al. Curcumin prevents high fat diet induced insulin resistance and obesity via attenuating lipogenesis in liver and inflammatory pathway in adipocytes. PLOS ONE. (2012) 7:e28784. doi: 10.1371/journal.pone.0028784

141. Ejaz A, Wu D, Kwan P, Meydani M. Curcumin inhibits adipogenesis in 3T3L1 adipocytes and angiogenesis and obesity in C57/BL mice. J Nutr. (2009) 139:919-25. doi: 10.3945/jn.108.100966

142. Chen HM, Li SJ, Chen HP, Wang QW, Li LS, Liu ZH. Obesity-related glomerulopathy in China: a case series of 90 patients. Am J of Kidney Dis. (2008) 52:58-65. doi: 10.1053/j.ajkd.2008.02.303

143. Miyazawa T, Nakagawa K, Kim SH, Thomas MJ, Paul L, Zingg J-M, et al. Curcumin and piperine supplementation of obese mice under caloric 
restriction modulates body fat and interleukin-1ß. Nutr Metab. (2018) 15:12. doi: 10.1186/s12986-018-0250-6

144. Akbari M, Lankarani KB, Tabrizi R, Ghayour-Mobarhan M, Peymani P, Ferns G, et al. The effects of curcumin on weight loss among patients with metabolic syndrome and related disorders: a systematic review and metaanalysis of randomized controlled trials. Front Pharmacol. (2019) 10:649. doi: $10.3389 /$ fphar.2019.00649

145. van Duynhoven J, Vaughan EE, Jacobs DM, Kemperman RA, van Velzen EJJ, Gross G, et al. Metabolic fate of polyphenols in the human superorganism. Proc Natl Acad Sci USA. (2011) 108(Suppl. 1):4531-8. doi: 10.1073/pnas.1000098107

146. Burapan S, Kim M, Han J. Curcuminoid Demethylation as an alternative metabolism by human intestinal microbiota. J Agric Food Chem. (2017) 65:3305-10. doi: 10.1021/acs.jafc.7b00943

147. Zam W. Gut Microbiota as a prospective therapeutic target for curcumin: a review of mutual influence. J Nutr Metab. (2018) 2018:1367984. doi: $10.1155 / 2018 / 1367984$

148. Tanoue T, Umesaki $\mathrm{Y}$, Honda K. Immune responses to gut microbiotacommensals and pathogens. Gut Microbes. (2010) 1:224-33. doi: 10.4161/gmic.1.4.12613

149. Le Chatelier E, Nielsen T, Qin J, Prifti E, Hildebrand F, Falony G, et al. Richness of human gut microbiome correlates with metabolic markers. Nature. (2013) 500:541-6. doi: 10.1038/nature12506

150. Sonnenburg JL, Bäckhed F. Diet-microbiota interactions as moderators of human metabolism. Nature. (2016) 535:56-64. doi: 10.1038/nature18846

151. Daniel H, Gholami AM, Berry D, Desmarchelier C, Hahne H, Loh G, et al. High-fat diet alters gut microbiota physiology in mice. ISME J. (2014) 8:295-308. doi: 10.1038/ismej.2013.155

152. Shen L, Liu L, Ji HF. Regulative effects of curcumin spice administration on gut microbiota and its pharmacological implications. Food Nutr Res. (2017) 61:1361780. doi: 10.1080/16546628.2017.1361780

153. Greiner AK, Papineni RVL, Umar S. Chemoprevention in gastrointestinal physiology and disease: natural products and microbiome. Am J Physiol Gastrointest Liver Physiol. (2014) 307:G1-15. doi: 10.1152/ajpgi.00044.2014

154. Bereswill S, Muñoz M, Fischer A, Plickert R, Haag LM, Otto B, et al. Anti-inflammatory effects of resveratrol, curcumin and simvastatin in acute small intestinal inflammation. PLoS ONE. (2010) 5:e15099. doi: 10.1371/journal.pone.0015099

155. Mohamed Sham Shihabudeen H, Hansi Priscilla D, Thirumurugan K. Cinnamon extract inhibits $\alpha$-glucosidase activity and dampens postprandial glucose excursion in diabetic rats. Nutr Metab. (2011) 8:46. doi: $10.1186 / 1743-7075-8-46$

156. Anand P, Murali KY, Tandon V, Murthy PS, Chandra R. Insulinotropic effect of cinnamaldehyde on transcriptional regulation of pyruvate kinase, phosphoenolpyruvate carboxykinase, and GLUT4 translocation in experimental diabetic rats. Chem Biol Interact. (2010) 186:72-81. doi: 10.1016/j.cbi.2010.03.044

157. Peng X, Cheng KW, Ma J, Chen B, Ho CT, Lo C, et al. Cinnamon bark proanthocyanidins as reactive carbonyl scavengers to prevent the formation of advanced glycation endproducts. J Agric Food Chem. (2008) 56:1907-11. doi: 10.1021/jf073065v

158. Zhang J, Wider B, Shang H, Li X, Ernst E. Quality of herbal medicines: challenges and solutions. Complement Ther Med. (2012) 20:100-6. doi: 10.1016/j.ctim.2011.09.004

159. Yuan J, Dieter MP, Bucher JR, Jameson CW. Application of microencapsulation for toxicology studies. III. Bioavailability of microencapsulated cinnamaldehyde. Fundam Appl Toxicol. (1993) 20:83-7. doi: $10.1093 /$ toxsci/20.1.83

160. Lopresti AL. The problem of curcumin and its bioavailability: could its gastrointestinal influence contribute to its overall healthenhancing effects? Adv Nutr. (2018) 9:41-50. doi: 10.1093/advances/ $\mathrm{nmx} 011$

161. Shen L, Ji HF. Bidirectional interactions between dietary curcumin and gut microbiota. Crit Rev Food Sci Nutr. (2019) 59:2896-902. doi: 10.1080/10408398.2018.1478388

162. An X, Bao Q, Di S, Zhao Y, Zhao S, Zhang H, et al. The interaction between the gut Microbiota and herbal medicines. Biomed Pharmacother. (2019) 118:109252. doi: 10.1016/j.biopha.2019.109252

Conflict of Interest: The authors declare that the research was conducted in the absence of any commercial or financial relationships that could be construed as a potential conflict of interest.

Copyright (ㅇ 2020 Arozal, Louisa and Soetikno. This is an open-access article distributed under the terms of the Creative Commons Attribution License (CC BY). The use, distribution or reproduction in other forums is permitted, provided the original author(s) and the copyright owner(s) are credited and that the original publication in this journal is cited, in accordance with accepted academic practice. No use, distribution or reproduction is permitted which does not comply with these terms. 